\title{
Exchange Flows in Tributary Creeks Enhance Dispersion by Tidal Trapping
}

\author{
Adrian Mikhail P. Garcia ${ }^{1,2}$ [ $\cdot$ W. Rockwell Geyer ${ }^{2} \cdot$ Noa Randall $^{3}$
}

Received: 16 February 2021 / Revised: 26 May 2021 / Accepted: 2 June 2021 / Published online: 13 July 2021

(C) The Author(s) 2021

\begin{abstract}
The North River estuary (Massachusetts, USA) is a tidal marsh creek network where tidal dispersion processes dominate the salt balance. A field study using moorings, shipboard measurements, and drone surveys was conducted to characterize and quantify tidal trapping due to tributary creeks. During flood tide, saltwater propagates up the main channel and gets "trapped" in the creeks. The creeks inherit an axial salinity gradient from the time-varying salinity at their boundary with the main channel, but it is stronger than the salinity gradient of the main channel because of relatively weaker currents. The stronger salinity gradient drives a baroclinic circulation that stratifies the creeks, while the main channel remains well-mixed. Because of the creeks' shorter geometries, tidal currents in the creeks lead those in the main channel; therefore, the creeks never fill with the saltiest water which passes the main channel junction. This velocity phase difference is enhanced by the exchange flow in the creeks, which fast-tracks the fresher surface layer in the creeks back to the main channel. Through ebb tide, the relatively fresh creek outflows introduce a negative salinity anomaly into the main channel, where it is advected downstream by the tide. Using high-resolution measurements, we empirically determine the salinity anomaly in the main channel resulting from its exchange with the creeks to calculate a dispersion rate due to trapping. Our dispersion rate is larger than theoretical estimates that neglect the exchange flow in the creeks. Trapping contributes more than half the landward salt flux in this region.
\end{abstract}

Keywords Dispersion $\cdot$ Exchange flow $\cdot$ Tidal trapping $\cdot$ Channel network

\section{Introduction}

The salinity distribution of an estuary impacts circulation patterns by introducing horizontal density gradients, which drive baroclinic exchange flows (Pritchard 1952a), and vertical density gradients (stratification), which can inhibit turbulent mixing (Bowden 1964). The salt intrusion in estuaries is determined from the balance between the river flow, which exports salt out of the estuary, and a combination of subtidal

Communicated by Lijun Hou

Adrian Mikhail P. Garcia

garciaap@mit.edu

1 MIT-WHOI Joint Program in Oceanography \& Applied Ocean Science \& Engineering, Cambridge, MA, USA

2 Woods Hole Oceanographic Institution, Woods Hole, MA, USA

3 US Geological Survey, Woods Hole Coastal \& Marine Science Center, Woods Hole, MA, USA (steady) and tidal dispersive processes, which import salt into the estuary (Pritchard 1952b; MacCready and Geyer 2010).

While the steady baroclinic circulation (Hansen and Rattray 1965; Chatwin 1976) is the primary driver of the landward salt transport in long estuaries where the salinity intrusion length extends much further than a tidal excursion, tidal dispersion processes (Hughes and Rattray 1980) are the dominant driver of the landward salt transport in short estuaries, where the salinity intrusion is similar in length to the tidal excursion (Chen et al. 2012). A notable distinction is that in long estuaries, the salinity intrusion decreases during spring tides due to greater vertical mixing which inhibits the baroclinic circulation (Lerczak et al. 2006), while in short estuaries, the salinity intrusion increases during spring tides due to stronger tidal currents (Ralston et al. 2010).

Tidal dispersion describes the net effect of tidal currents on the horizontal spreading of scalars (Fischer 1976; Zimmerman 1986; Geyer and Signell 1992). The corresponding salt flux is expressed through the tidal 
correlation between the tidally varying velocity and salinity, and thus depends on the size of the tidal amplitudes of velocity and salinity and the relative phasing between them. If velocity and salinity are in perfect quadrature, the tidal correlation is identically zero. However, when velocity and salinity are shifted out of quadrature by nonlinear processes, the tidal salt flux is nonzero and is typically directed landward (Hunkins 1981). Dronkers and van de Kreeke (1986) distinguish between a local and nonlocal tidal salt flux, which result from decomposing the tidally varying velocity and salinity into their cross-sectionally varying (local) and cross-sectionally averaged (nonlocal) components. At a given cross section, the local tidal salt flux represents the effects of oscillatory shear dispersion (Bowden 1965; Chatwin 1975), resulting from differential advection due to velocity shear and the effects of transverse mixing and secondary circulation, which shift velocity and salinity out of quadrature over the cross section. The nonlocal salt flux results from tidal correlations of the cross-sectional averages of salinity and velocity, which can be shifted out of quadrature by spatiotemporal variations of the local salt flux within a tidal excursion from a given cross section (Dronkers and van de Kreeke 1986). Thus, the nonlocal salt flux at a given location is significant within a tidal excursion of highly dispersive regions, such as near the mouth due to the jet-sink exchange of oceanic water into the estuary (Stommel and Farmer 1952; Chen et al. 2012) and reaches of the main channel where tidal trapping-lateral exchange with shoals and side channels-occurs (Okubo 1973). In estuaries with complex morphologies such as intertidal mudflats, marshes, and channel systems, the nonlocal process of tidal trapping can produce significant landward salt flux (Dronkers and van de Kreeke 1986).

Tidal trapping is the mechanism by which shoals, side channels, and embayments contribute to longitudinal dispersion in the estuary main channel (Schijf and Schonfeld 1953; Okubo 1973; Dronkers 1978; Fischer et al. 1979; MacVean and Stacey 2011). For oscillatory flow in branching channel systems, the effective dispersion can be substantially larger than in single channels due to the additional flow distortions caused by channel splitting (Smith 1996) and phase differences in the oscillatory currents (Schijf and Schonfeld 1953). In the main channel of an estuary, phasing between velocity and tidal elevation is usually intermediate between a progressive and standing wave due to a combination of inertial and bathymetric effects (Friedrichs 2011). However, within side channels such as tributaries and embayments, the shorter length causes the phase to be closer to a standing wave (Friedrichs 2011). Thus, as the tide rises, the side channels or "traps" fill with water from the main channel, but once the tide begins to fall, the traps empty back into the main channel while it still continues to flood (Schijf and Schonfeld 1953).

A conceptual schematic of tidal trapping due to a tributary creek is illustrated in Fig. 1. The out-of-phase exchange between the creek and main channel introduces a freshwater anomaly into the main channel at the junction. The tidal dispersion associated with trapping depends on the magnitude of this negative salinity anomaly, which is advected downstream in the main channel during ebb tide. Physically, the relatively fresh creek outflow reduces the amount of salt that exits the region downstream of the junction during ebb tide as compared to the salt that enters
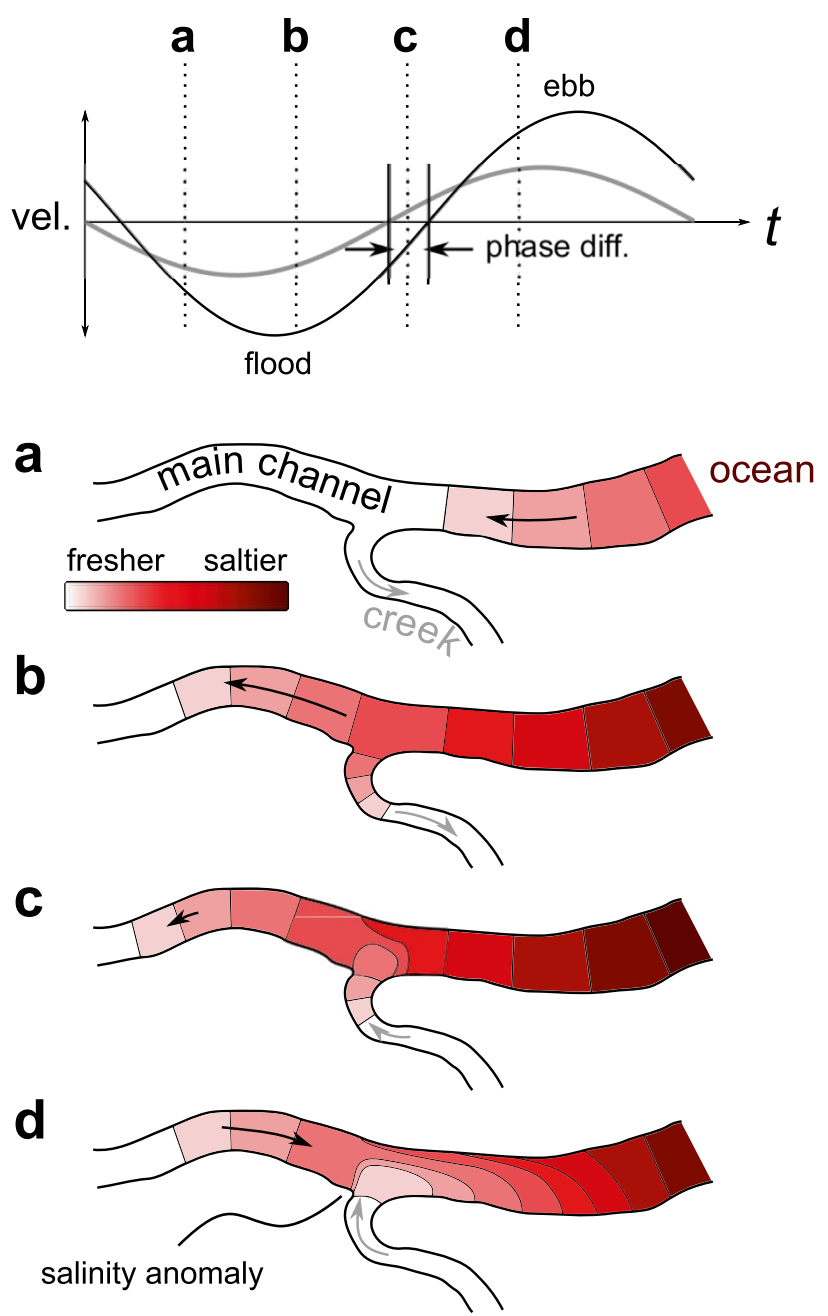

Fig. 1 Tidal trapping due to a tributary creek: (a) salt is advected into the estuary main channel during flood tide; (b) the creek fills with water from the main channel, inheriting an axial salinity gradient; (c) the creek reverses flow direction before the main channel because its tidal phasing is like a standing wave due to its shorter geometry, so it never fills with the saltiest water which passes the junction; (d) the creek empties out as a freshwater plume into the main channel during ebb tide, introducing a negative salinity anomaly into the main channel. The time-series in the upper panel depicts relative velocity magnitude and phasing in the main channel (black) and the creek (gray) 
during flood, resulting in a net landward transport of salt over a tidal cycle. This landward transport is balanced by the advective seaward transport due to the river flow.

Dispersion due to tidal trapping was most notably analyzed by Okubo (1973), who modeled the exchange between traps and the main channel as a diffusive source/ sink term in the 1-D transport equation. Applying the concentration moment analysis of Aris (1956), he determined an analytical expression for the trapping dispersion for the case of continuous lateral traps,

$K_{\text {trap }, \mathrm{D}}=\frac{r U^{2}}{\omega}\left(\frac{\omega / k}{2(1+r)^{2}(1+r+\omega / k)}\right)$,

where $K_{\text {trap,D }}$ is the dispersion coefficient due to tidal trapping, $r$ is the ratio of trap volume to channel volume, $U$ is the tidal velocity amplitude, $k$ is the exchange rate in the traps (typically of the order $\sim 10^{-4} \mathrm{~s}^{-1}$ ), and $\omega=2 \pi / T$ is the tidal radian frequency where $T=12.4 \mathrm{~h}$ is the M2 tidal period. This parametrization highlights the key dependence of trapping dispersion on the size and exchange timescale of the traps, the square of the tidal velocity amplitude, and the tidal period. The scaling represents a tidal velocity scale times the tidal excursion length times a nondimensional factor much smaller than 1 depending on the geometry and exchange rate between the traps and the main channel. The inverse of the exchange rate defines a residence timescale $k^{-1}$ which corresponds to how long a parcel of fluid spends in the trap before it returns to the main channel. As this timescale becomes longer, the dispersion associated with the trapping mechanism becomes larger because the parcel of fluid which entered the trap will be further away from the corresponding parcel which remained in the main channel. Applying Eq. (1) to the Mersey River estuary with an arbitrary exchange rate of $k=1 \times 10^{-4} \mathrm{~s}^{-1}$, Okubo (1973) found reasonable agreement with the observed values of dispersion rates. However, this parametrization does not explicitly represent the physics of the exchange process between the traps and main channel, and even Okubo (1973) admitted that "a precise knowledge of the exchange mechanism between the main body of water and the trap would replace $k$ by more appropriate parameters."

MacVean and Stacey (2011) proposed an alternative framework which analyzed tidal trapping due to side channels by treating them as an advective-rather than diffusive-source/sink term out-of-phase with the main channel. Applying a similar analysis as Okubo (1973), they calculated the effective dispersion rate for a series of idealized cases considering different horizontal mixing scenarios in the trap. For a branching channel system that is vertically and laterally well-mixed, they determined an expression for the trapping dispersion,
$K_{\text {trap,A }}=\frac{\epsilon U^{2}}{\omega}\left[\sin \alpha \cos \alpha\left(\frac{3 \cos \alpha+32 \sin \alpha}{12 \pi}\right)\right]$,

where $\epsilon \sim r$ is the ratio of salt mass entering and exiting the trap to the salt mass of the main channel and $\alpha$ is the radian phase difference between velocity in the main channel and the trap. Applying their parametrization to breached salt ponds in South San Francisco Bay, MacVean and Stacey (2011) obtained significantly smaller dispersion rates compared to the Okubo (1973) parametrization, for which they used an exchange rate $k=T^{-1}$. Given the unrealistically large value they obtained using the Okubo (1973) parametrization, they concluded that their framework, which accounts for the velocity phase difference between the main channel and the traps, more accurately represents the trapping dispersion in multi-channel systems where the exchange between the main channel and the traps is an advective process, rather than a diffusive one.

In order to test the theoretical results and compare with observations from previous studies, we use high-resolution measurements from a combination of moored instruments, shipboard surveys, and aerial drone imagery to characterize the tidal trapping mechanism in the tributary creeks of a salt marsh estuary and provide an empirical measure of the associated dispersion rate. The "Methods" section describes the field site and experimental setup. In the "Results" section, we present detailed observations of transport processes in the main channel and the creeks. Then, in the "Analysis" section, we use our measurements to calculate a dispersion rate due to the trapping mechanism by quantifying the salinity anomaly in the main channel resulting from its lateral exchange with the creeks. In the "Discussion" section, we compare our empirical estimate of the dispersion rate with predictions from theory and discuss the physics and implications of the exchange mechanism between the main channel and the creeks. We provide a summary of our key findings in the "Conclusions" section.

\section{Methods}

\section{Field Site}

We conducted a field campaign consisting of time-series measurements, shipboard surveys, and aerial drone photography during July-August 2018 in the North River (Marshfield, MA), shown in Fig. 2. This estuary system is connected to Massachusetts Bay at its mouth and includes a main channel joined by several smaller tributaries. The channels are surrounded by salt marshes that become inundated during spring high tide. Our study area was located about $5 \mathrm{~km}$ upstream from the mouth and encompassed two tributary creeks, Stony Brook and Cove Brook, and the adjacent 


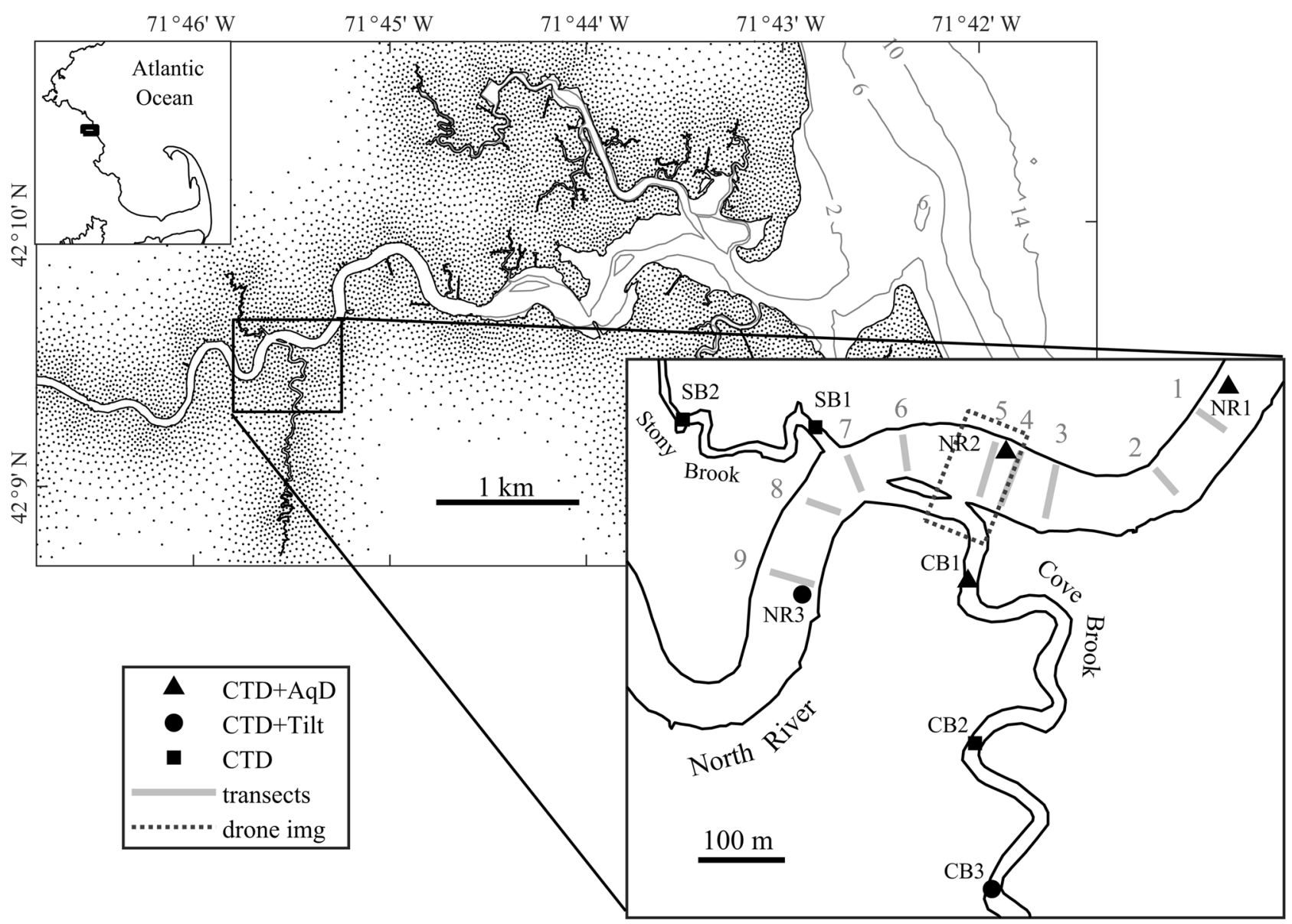

Fig. 2 Map of study area in the North River estuary with tributaries Stony Brook and Cove Brook. Locations of moored instruments, survey transects, and drone image footprint are labeled. The ocean (Mas-

$800 \mathrm{~m}$ reach in the main channel (Fig. 2). Estuarine conditions range from well-mixed to partially mixed depending on tidal conditions and river discharge. Throughout the measurement period, the tidal range varied over the spring-neap cycle from 2.2-3.2 $\mathrm{m}$ at the study site (Fig. 3a). The crosssectionally averaged tidal current amplitudes ranged from 0.3 to $0.6 \mathrm{~m} \mathrm{~s}^{-1}$, corresponding to tidal excursions of about 4-9 km, while the salinity intrusion was estimated to vary from 8 to $14 \mathrm{~km}$ in length. River discharge was obtained from an upstream gaging station (USGS 01,105,730) and scaled by a factor of 2.3 based on the ratio of the overall watershed area of the estuary to the gauged watershed area. The combined watersheds of the tributary creeks were less than $3 \%$ of the total catchment area at the study site. River flow varies seasonally, with average peak discharges during the spring freshet of around $50 \mathrm{~m}^{3} \mathrm{~s}^{-1}$ and low monthly averages during the summer of $0.3-2 \mathrm{~m}^{3} \mathrm{~s}^{-1}$. During this period of summer observations, the base river discharge was about $0.3-0.5 \mathrm{~m}^{3} \mathrm{~s}^{-1}$, with peaks up to $2 \mathrm{~m}^{3} \mathrm{~s}^{-1}$ during rain events (Fig. 3b). Although the discharge in this estuary is low, the sachusetts Bay) is located to the east, and the study site is about $5 \mathrm{~km}$ from the mouth of the estuary. Bathymetry contour intervals are $4 \mathrm{~m}$

cross-sectional areas are small $\left(\sim 300 \mathrm{~m}^{2}\right)$, so the influence of freshwater is not negligible.

\section{Moorings}

Conductivity-temperature-depth (CTD) sensors were deployed at moorings along the main channel and tributary creeks (see Fig. 2) to measure bottom salinity and tidal elevation every minute. At the moorings NR1, NR2, and CB1 (see Fig. 2), surface CTDs were deployed to provide a measure of stratification. Toward the end of the deployment, salinity measurements from the bottom CTD were contaminated by biofouling, resulting in erroneously fresh bottom salinities. The bottom salinity values were corrected for biofouling using surface sensors to adjust their values proportionately upward to eliminate density inversions, based on the ratio between bottom and surface salinities at the end of each flood tide.

Bottom-mounted Aquadopp profilers (Nortek) were deployed at NR1, NR2, and CB1 (see Fig. 2) to measure 


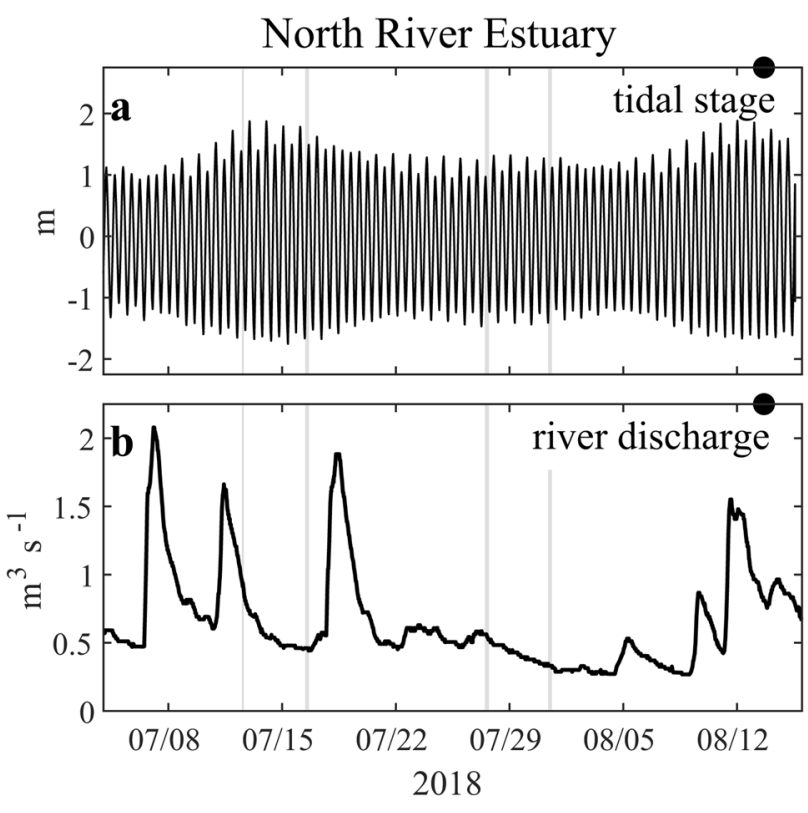

Fig. 3 Forcing conditions in the North River estuary during the study: (a) river discharge, (b) tidal elevation at NR2. The gray shaded bars indicate periods of shipboard surveys and the black circle indicates the time of the drone imagery

velocity profiles over $0.2 \mathrm{~m}$ bins at a sampling interval of $2 \mathrm{~min}$ using an averaging period of $20 \mathrm{~s}$ at a ping rate of $1 \mathrm{~Hz}$. Due to marsh vegetation occasionally getting caught on some of the moorings and covering the Aquadopp sensors, velocity time-series at NR1 and CB 1 are discontinuous or incomplete. Shipboard velocity surveys at the transects near the NR2 mooring revealed a marked lateral gradient in streamwise velocity during flood tide, which resulted in an asymmetry in the magnitudes of the ebb and flood currents measured at the NR2 mooring. At NR3 and CB3, tilt current meters were deployed to measure point velocities at approximately $1 \mathrm{~m}$ above the bed every minute. The measurements from the tilt meters were converted to EastNorth-Up (ENU) velocities using a standard tilt-to-speed curve and factory calibration values. The horizontal velocities were rotated into the direction of maximum variance to achieve the stream-wise and stream-normal velocity components $(u, v)$.

\section{Shipboard Surveys}

During the deployment period, shipboard surveys were conducted with a Nortek Signature 1000 acoustic Doppler current profiler (ADCP) and a profiling CTD across nine transects in the main channel and along the lengths of the creeks. Four days of surveys were completed, corresponding to periods of spring ebb (July 12), spring flood (July 16), neap ebb (July 27), and neap flood (July 31). In this paper, we focus on the neap ebb measurements from July 27 , since they provide the most complete dataset and clearest visualization of the tidal trapping mechanism.

During transects, the boat traveled at a slow speed of about $0.75 \mathrm{~m} \mathrm{~s}^{-1}$ to optimize the horizontal resolution of ADCP measurements. The ADCP measured velocity over $0.3 \mathrm{~m}$ bins with a sampling rate of $1 \mathrm{~Hz}$ and a ping rate of $4 \mathrm{~Hz}$. Velocity was measured in beam coordinates then transformed to ENU during post-processing. The bottom tracking velocity was subtracted from the measured velocity to obtain the Eulerian velocity. A mask was applied to the velocity based on blanking distance and distance from the bottom. Each velocity measurement was rotated towards the direction of the depth-averaged velocity to obtain the stream-wise velocity. This results in a depth-averaged stream-normal velocity equal to zero. To reduce noise, a 2-D moving boxfilter was applied to smooth the velocity data over approximately $10 \mathrm{~m}$ horizontally and $1 \mathrm{~m}$ vertically.

The CTD used for shipboard surveys measured data at a sampling rate of $16 \mathrm{~Hz}$, corresponding to a vertical resolution of about $0.1 \mathrm{~m}$. A protective frame was used to prevent mud from entering the conductivity sensor and affecting the measurements when the CTD reached the bed. During crosschannel transects, CTD tow-yo's were conducted to maximize horizontal spatial resolution $(\sim 10 \mathrm{~m})$. For the alongcreek profiles, CTD casts were taken at regular time intervals to optimize spatial coverage and resolution $(\sim 50 \mathrm{~m})$. Only data from down-casts were used, and these values were then interpolated onto a regularly spaced vertical grid during post-processing.

The position of the shipboard measurements was interpolated based on the time record from an onboard global positioning system (GPS), which recorded latitude and longitude at $1 \mathrm{~Hz}$. Latitude and longitude were then converted to a curvilinear (stream-wise, stream-normal) coordinate system based on the corresponding channel centerline. In this coordinate transformation, zero in the stream-wise coordinate is located at the mouth of the channel and negative distance goes upstream. The stream-normal coordinate is zero at the centerline and positive (negative) to the right (left) when looking upstream.

\section{Drone Imagery}

On August 13 during spring conditions, drone imagery was obtained during early ebb near the junctions of Cove Brook and the North River. A DJI Phantom 4 drone was flown overhead the junction at an altitude of about $100 \mathrm{~m}$ above ground level, recording $24-\mathrm{Hz}$ video footage with an image footprint of $160 \mathrm{~m}$ by $90 \mathrm{~m}$ and a resolution of $4.2 \mathrm{~cm}$ per pixel. During this time, 2 boats deployed surface drifters upstream of the drone image in both the main channel and the creek. Additionally, one of the boats 
conducted ADCP and CTD surveys along transects across the mouth of the creek and across the main channel into the creek plume. Particle tracking velocimetry (PTV) was applied to the individual drifters in the drone video to estimate surface velocities, following a procedure similar to Tauro et al. (2019). First, the images were converted into binary images based on a threshold in the image intensity. Afterward, a filter was applied to isolate the pixels corresponding to the drifters based on the number of points in each connected feature. The positions of the centroids for each drifter feature were then calculated and tracked from frame to frame, enabling the calculation of a Lagrangian velocity for each drifter. Since the camera lens showed very little distortion, the pixel dimensions were considered to be constant throughout the entire image footprint, as done by Streßer et al. (2017). The horizontal scale used to convert the pixel dimensions to physical space was determined from ground measurements of a stationary pier in the image footprint. Velocities were then smoothed by applying a 4-s lowpass filter.

\section{Results}

\section{Estuarine Conditions}

Figure 4 provides an overview of estuarine conditions and the effective dispersion rate over the course of the 45-day observation period at the NR2 mooring. The effective dispersion rate was estimated from a steady-state balance between the advective river flux and diffusive salt flux,

$Q_{f} s_{0} \approx K A_{0}\left(\frac{\partial s_{0}}{\partial x}\right)$

where $Q_{f}$ is river discharge, $K$ is the effective dispersion rate, $s_{0}$ is the tidally averaged cross-sectional salinity, $A_{0}$ is the tidally averaged cross-sectional area, and $\partial s_{0} / \partial x$ is the tidally averaged along-channel salinity gradient. Tidal averages were calculated using a 33-h low-pass filter, following Lerczak et al. (2006). To obtain a local estimate of $\partial s_{0} / \partial x$ at NR2, we estimated its value from the maximum salinity
Fig. 4 Time-series at mooring NR2 over the measurement period. (a) Freshwater velocity, defined as $u_{f}=Q_{f} / A_{0}$. (b) Tidally varying velocity (thin line) and tidal velocity amplitude (thick line), which is scaled by a factor to account for the ebb-flood asymmetry due to lateral velocity shear at NR2. (c) Tidally varying salinity and stratification (thin lines) and tidally averaged salinity (thick line). (d) Tidally averaged longitudinal salinity gradient. (e) Effective dispersion rate using different lagged filters to account for the estuarine adjustment timescale. The gray shaded bar indicates periods of shipboard surveys
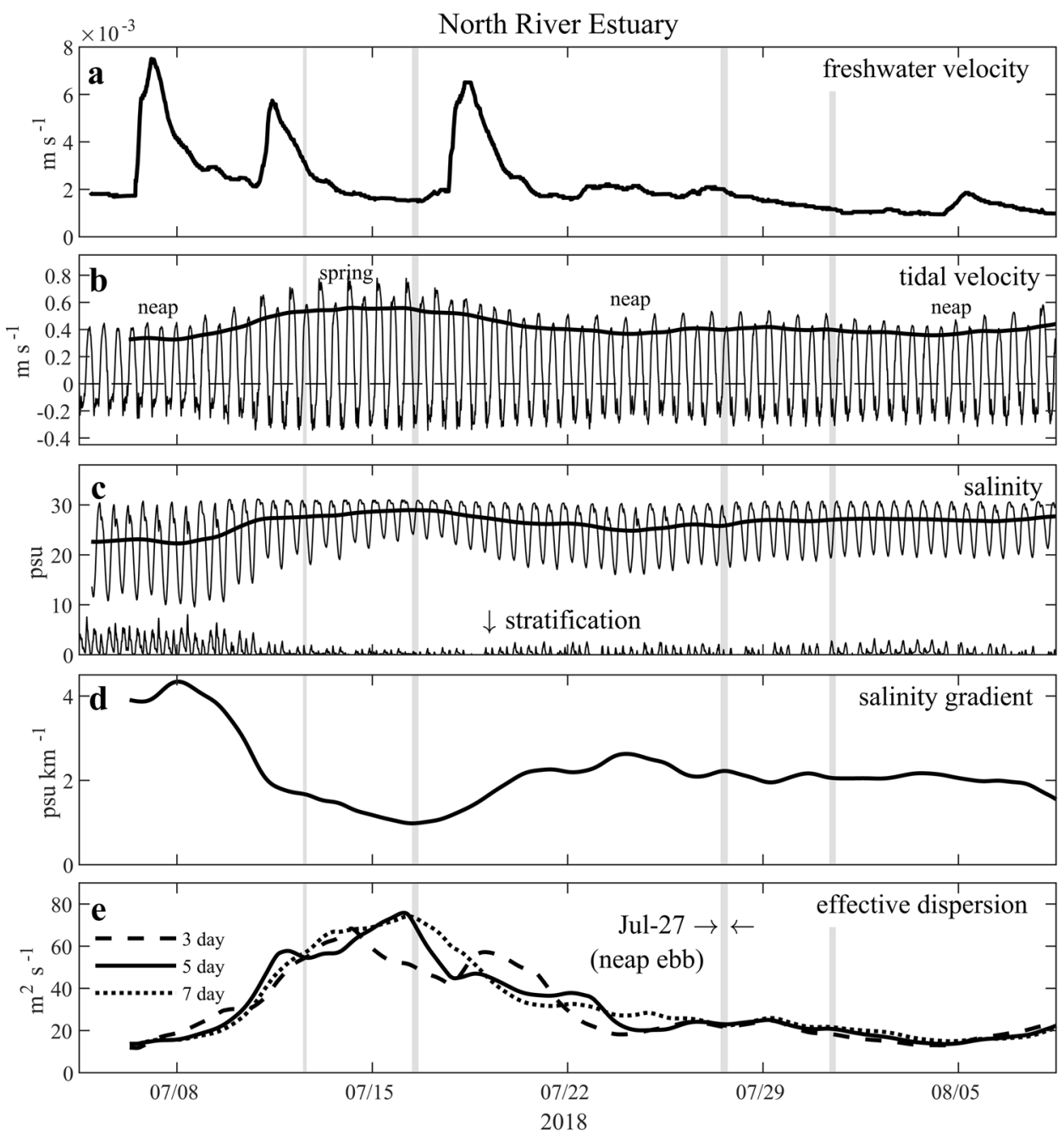
range per tidal cycle divided by the tidal excursion (Banas et al. 2004; MacVean and Stacey 2011). We compared this calculation of the salinity gradient with upstream, downstream, and centered differences of salinity between the 3 main channel moorings and found that this method provided a robust measure of the salinity gradient.

We note that directly estimating the dispersion rate from the instantaneous river discharge does not accurately represent the salt balance in the North River following episodic discharge events, due to the finite timescale of estuarine adjustment. The timescale of adjustment for the salinity distribution in estuaries dominated by tidal processes is inversely dependent on the advective velocity due to river discharge (Kranenburg 1986). Based on conditions in the North River during the 2018 summer observations, that timescale was estimated to be in the range of 3-7 days. To account for this time dependence, we first apply a boxcar filter to $Q_{f}$ using time lags of 3, 5, and 7 days before calculating $K$ in Fig. 4 e. Note that during the latter half of the deployment when river discharge is fairly constant, all 3 estimates of $K$ converge.

Stratification was largest at the beginning of the observation period during neap conditions and relatively high river discharge (Fig. 4c). Throughout this period of measurements, this region of the estuary is never consistently stratified over an entire tidal cycle-rather, stratification varies tidally. During spring conditions when tidal velocities were largest, stratification essentially vanishes. The along-axis salinity gradient decreased while salinity increased during spring conditions, indicating a lengthening of the salt intrusion. Over the period of summer measurements, the effective dispersion rate required to balance the advective river outflow varied from about $10-80 \mathrm{~m}^{2} \mathrm{~s}^{-1}$ (Fig. 4e). The effective dispersion rate was primarily dependent on the spring-neap variability and was largest for spring tides and smallest for neap. For the period of shipboard surveys during the neap ebb on July 27 , the effective dispersion rate was $23 \mathrm{~m}^{2} \mathrm{~s}^{-1}$.

\section{Salt Balance in the Main Channel and Creek}

The mechanisms which produce the effective dispersion rate can be identified by decomposing the subtidal salt flux at a given cross section into components resulting from different combinations of temporal and spatial correlations of velocity and salinity (Fischer et al. 1979; Hughes and Rattray 1980; Dronkers and van de Kreeke 1986; Lerczak et al. 2006). Here, following Dronkers and van de Kreeke (1986), we separate the cross section into a finite number of differential area elements $(d A)$ which expand and contract tidally and then decompose velocity and salinity into three orthogonal components which are tidally and cross-sectionally averaged $\left(u_{0}, s_{0}\right)$, tidally varying and cross-sectionally averaged $\left(u_{1}, s_{1}\right)$, and tidally varying and cross-sectionally varying $\left(u_{2}, s_{2}\right)$. The velocity components are defined by Eqs. (4-6):

$u_{0}=\frac{\left\langle\int u d A\right\rangle}{A_{0}}$,

$u_{1}=\frac{\int u d A}{\int d A}-u_{0}$

$u_{2}=u-u_{1}-u_{0}$,

where $u_{0}$ is the steady cross-sectional average velocity, $u_{1}$ is the tidally varying cross-sectional average velocity, and $u_{2}$ is the tidally varying deviation from the cross-sectional average velocity. Angle brackets indicate tidal averaging and $A_{0}=\left\langle\int d A\right\rangle$ is the tidally averaged cross-sectional area. The cross-sectionally varying component (velocity shear) can be further decomposed into a steady component and a tidally varying component, defined by Eqs. (7-8):

$u_{3}=\frac{\left\langle u_{2} d A\right\rangle}{\langle d A\rangle}$

$u_{4}=u_{2}-u_{3}$,

where $u_{3}$ is the steady component of the shear and $u_{4}$ is the tidally varying component. Salinity is decomposed in an identical manner, and the subtidal salt flux is given by

$$
\begin{aligned}
F & =u_{0} s_{0} A_{0}+\left\langle u_{1} s_{1} A\right\rangle+\int u_{3} s_{3} d A_{0}+\left\langle\int u_{4} s_{4} d A\right\rangle \\
& =-Q_{0} s_{0}+F_{1}+F_{3}+F_{4} .
\end{aligned}
$$

Thus, the total salt flux through the section is decomposed into four components: the advective outflow due to $Q_{0}$, the river discharge; the nonlocal tidal salt flux $F_{1}$ which results from the phasing between the tidally varying, cross-sectionally averaged velocity and salinity; the local steady salt flux $F_{3}$ due to steady shear dispersion; and the local tidal salt flux $F_{4}$ due to the deviations from the cross-sectionally and tidally averaged velocities and salinities (Dronkers and van de Kreeke 1986). At steady state, the total salt flux $F$ must be zero. The salt fluxes are related to the effective dispersion rate by $F_{1}+F_{3}+F_{4}=-K A_{0}\left(\partial s_{0} / \partial x\right)$.

Using this framework, we decomposed the salt fluxes at NR1, located in the main channel seaward from the junction with the creek, and CB1, located in the creek near the mouth (see Fig. 2). Although the velocity time-series at NR1 are continuous only for the latter half of the deployment, this location had less lateral variability than NR2 and enabled more accurate calculations of the salt fluxes. In the creek, the velocity measurements were limited to a four-day period because the sensor was fouled by detritus within several days 
of deployment. Since the freshwater velocity is $2-3$ orders of magnitude smaller than the tidal velocities, the accurate measurement of the steady, cross-sectional average velocities is difficult to obtain (Hunkins 1981). Therefore, we use the river discharge, $Q_{f}$ rather than measured steady volumetric flow, $Q_{0}=u_{0} A_{0}$ to calculate the advective salt flux. Tidally varying cross-sectional area was calculated using the bathymetry by fitting a power law to the hypsometry at the mooring locations. We separated each cross section at the midpoint of the water column into two depth-proportional layers with salinities of the bottom and surface CTDs. Although our time-series only provided vertical structure, our shipboard surveys confirmed that lateral variations of velocity and salinity at NR1 were insignificant. While we did not complete any shipboard transects across the creek, we expect limited lateral structure due to the narrow channel width of about $20 \mathrm{~m}$. To calculate the layer averaged velocities, we average the velocity measurements from the bins within the top and bottom halves of the water column. At NR1, tidally averaged values were calculated using a 33-h low-pass filter. However, due to the short record of data available at CB1, tidal averages in the creek were calculated over individual tidal cycles starting at flood tide and ending after ebb.

Throughout most of the measurement period, the advective river flux in the North River near the creek junction is balanced almost entirely by the nonlocal salt flux (Fig. 5).

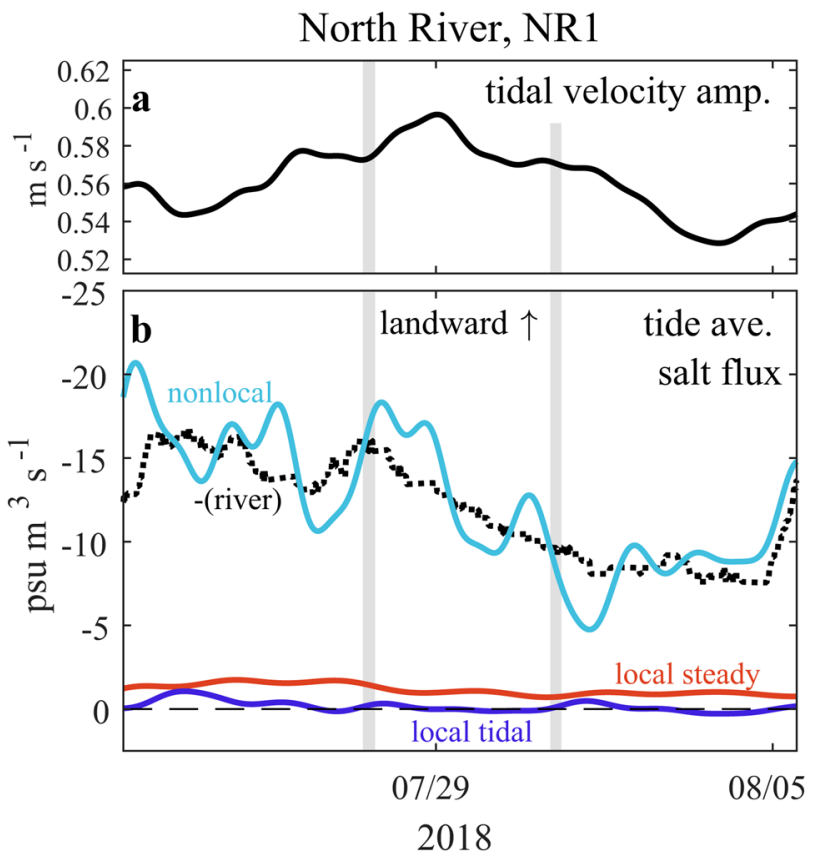

Fig. 5 Salt balance in the North River. Tidal velocity amplitudes are shown in (a) and tidally averaged salt fluxes are shown in (b). The advective river outflow (black) is primarily balanced by the nonlocal salt flux (cyan), while the local steady (red) and local tidal (blue) components are negligible
The local salt fluxes—-both steady and tidal—are relatively insignificant, owing to strong transverse and vertical mixing which inhibit shear dispersion over the cross section. Although the salt fluxes are not resolved during the spring tide, we expect that the nonlocal salt flux will continue to be the dominant mode of landward salt transport because the stronger tidal currents will only strengthen mixing at this location. The large nonlocal salt flux indicates that strong shear dispersion is occurring elsewhere within one tidal excursion of the cross section at NR1 (Dronkers and van de Kreeke 1986). The source of this nonlocal salt flux later will be investigated later in the discussion.

The salt balance in the creek (Fig. 6) is maintained by the local steady salt flux, which is directed landward, and the local tidal and nonlocal salt fluxes, which are directed seaward, i.e., counter-gradient. Note that a distinct diurnal inequality is evident in the salt fluxes. For the tidal cycles when tidal velocities are larger, the net salt flux is seaward. On the following cycle when tidal velocities are smaller, the local steady salt flux increases, and the net salt flux is landward. The landward local steady salt flux is potentially explained by residually stratified conditions and an estuarine exchange flow, which is landward at the bottom and seaward at the surface. We explore this vertical structure in the subsections below. The tidal local salt flux can be seaward if the creek is

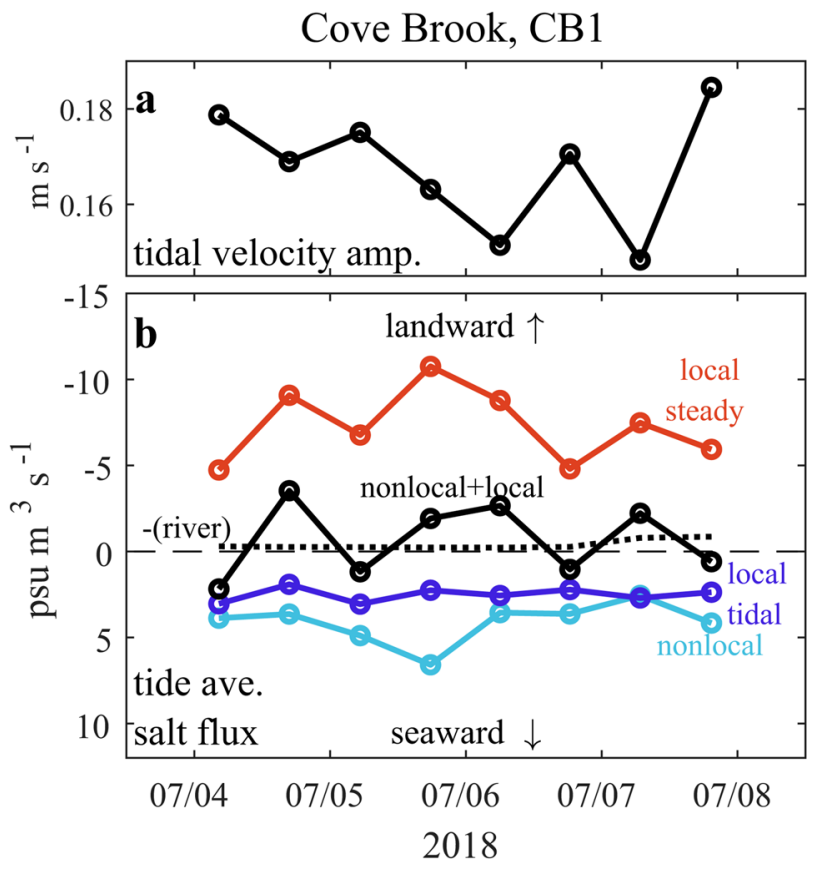

Fig. 6 Salt balance in Cove Brook for individual tidal cycles. Tidal velocity amplitudes are shown in (a) and tidally averaged salt fluxes are shown in (b). The river outflow (black, dashed) is negligible, and the primary balance is between the local steady salt flux (red) and both the nonlocal (cyan) and local tidal salt flux (blue). The sum of the nonlocal and local components is shown by the black solid line, which effectively represents the net salt flux 
stratified and the vertical shear is monotonic during periods of the flood tide. The opposing fluxes by different mechanisms are the result of the spatial complexity of the junction region, which leads to significant nonlocal salt flux, based on the analysis by Dronkers and van de Kreeke (1986). In the following sections, we examine how variations in salinity and flow structure between the creeks and the main channel are coupled by the exchange mechanism between them.

\section{Hydrographic Surveys of Tidal Trapping}

The impact of the exchange between the creek and the main channel on their salinity structures is evident in the shipboard hydrographic data during the neap ebb tide surveys on July 27 (Fig. 7). The first survey (a) occurs while both the main channel and the creek are flooding. The cross section in the main channel is generally well-mixed, but the creek

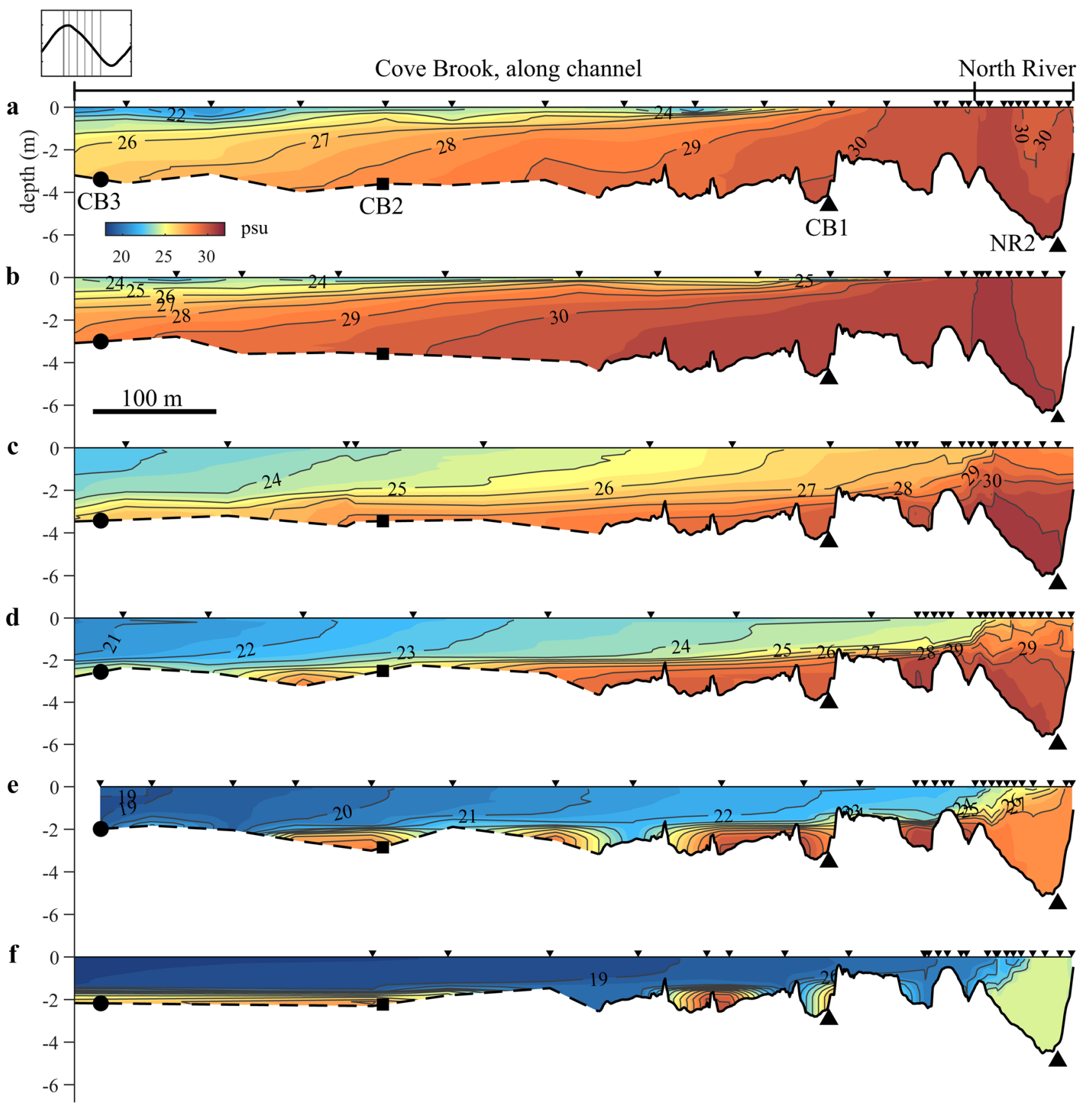

Fig. 7 Hydrographic surveys of salinity along Cove Brook and across the North River (transect 5) taken over a period of ebb tide (a)-(f) during neap conditions on July 27. Black triangles along the top axis indicate CTD casts. Mooring locations are labeled in (a).
Bathymetry data is shown by the solid black line and estimates of the bathymetry from the CTD casts are shown by the dashed black line. Periods of individual surveys are designated by gray shaded lines in the upper left plot of the tidal time-series 
becomes strongly stratified upstream from the mouth. The second survey (b) occurs around the end of flood tide in the main channel. In the creek, the 30 psu isohaline becomes nearly horizontal, indicating a relaxation of the horizontal pressure gradient, i.e., "lock exchange." During the third survey (c), the creek begins ebbing into the main channel with a salinity of about 27 psu and stratifies the main channel. The bottom layer in the creek becomes disconnected due to the presence of the sill near the junction. During the fourth survey (d), the fresher creek water continues to discharge into the main channel, spreading across the entire channel width. At that time, the outflow of the creek is similar in magnitude to the volumetric flow through the main channel. However, during the fifth survey (e), the velocity in the main channel relative to the creek has increased, thus the influence of the creek outflow on the salinity of the main channel is smaller and the fresh surface layer thins. By the sixth survey (f), the creek outflow is confined to a small plume on one side of the main channel. In the creek, pools of salty water are trapped behind the sill near the junction of the creek with the main channel, indicating that fresher water leaves the creek before the saltiest water.

We note that the creek outflow remains fresher than the main channel through ebb tide despite the absence of any significant freshwater source. The low salinity water at the upstream end of the creek thus must have entered during the early flood, when the water in the adjacent North River was at its minimum. Thus, although the creek has an axial salinity distribution like an estuary, it is in fact an extension of the main channel, from which it derives its salinity structure when it fills during flood tide. Yet, while water from the main channel is well-mixed when it enters the creek, it leaves the creek having significant stratification. Therefore, the freshwater anomaly observed in the main channel during ebb tide results strictly from the rearrangement of water from the main channel after it enters the creek, rather than the addition of freshwater. That is, the exchange between the main channel and the creeks impacts the longitudinal salinity structure (and consequentially dispersion) in the main channel without inputting new freshwater.

\section{Tidal Variation of Salinity and Velocity}

The time-series measurements in the North River and Cove Brook (Fig. 8) demonstrate the influence of the creek outflow on the salinity in the main channel through multiple tidal cycles. Over the time record shown in Fig. 8, the impact of the diurnal inequality is evident, most notably in how it impacts the patterns of stratification in the creek. During this period, the tides are larger at night than during daytime. For example, the high tide occurring after the shipboard surveys on July 27 was about $0.34 \mathrm{~m}$ higher than the one which occurred during the surveys. Tidal currents are also faster, especially for the peak in creek velocity at the beginning of ebb tides. Because the marsh is located at an elevation of about $1.1 \mathrm{~m}$ with respect to the mean tidal level, the inundation and draining of the marsh only occur during the tides at night over this time record. The larger tidal currents at night increase turbulent mixing, and as a result the creek fluctuates between well-mixed and stratified conditions on alternate ebb tides.
Fig. 8 Time-series of (a) tidal elevation, (b) velocity, and (c) salinity for the North River (black) and Cove Brook bottom (red) and surface (blue) measurements. The gray shaded bar indicates the period of shipboard surveys shown in Fig. 7. Tidal elevations at high and low water are labeled in (a), along with the marsh elevation. Tidal elevation and salinities are from the moorings at NR2 and CB1. Velocities are from NR1 and CB3. Only the surface salinity is shown for the North River. The "creek effect" corresponds to the salinity deficit in the main channel at the beginning of each ebb tide, resulting from the relatively fresh creek outflows entering the North River
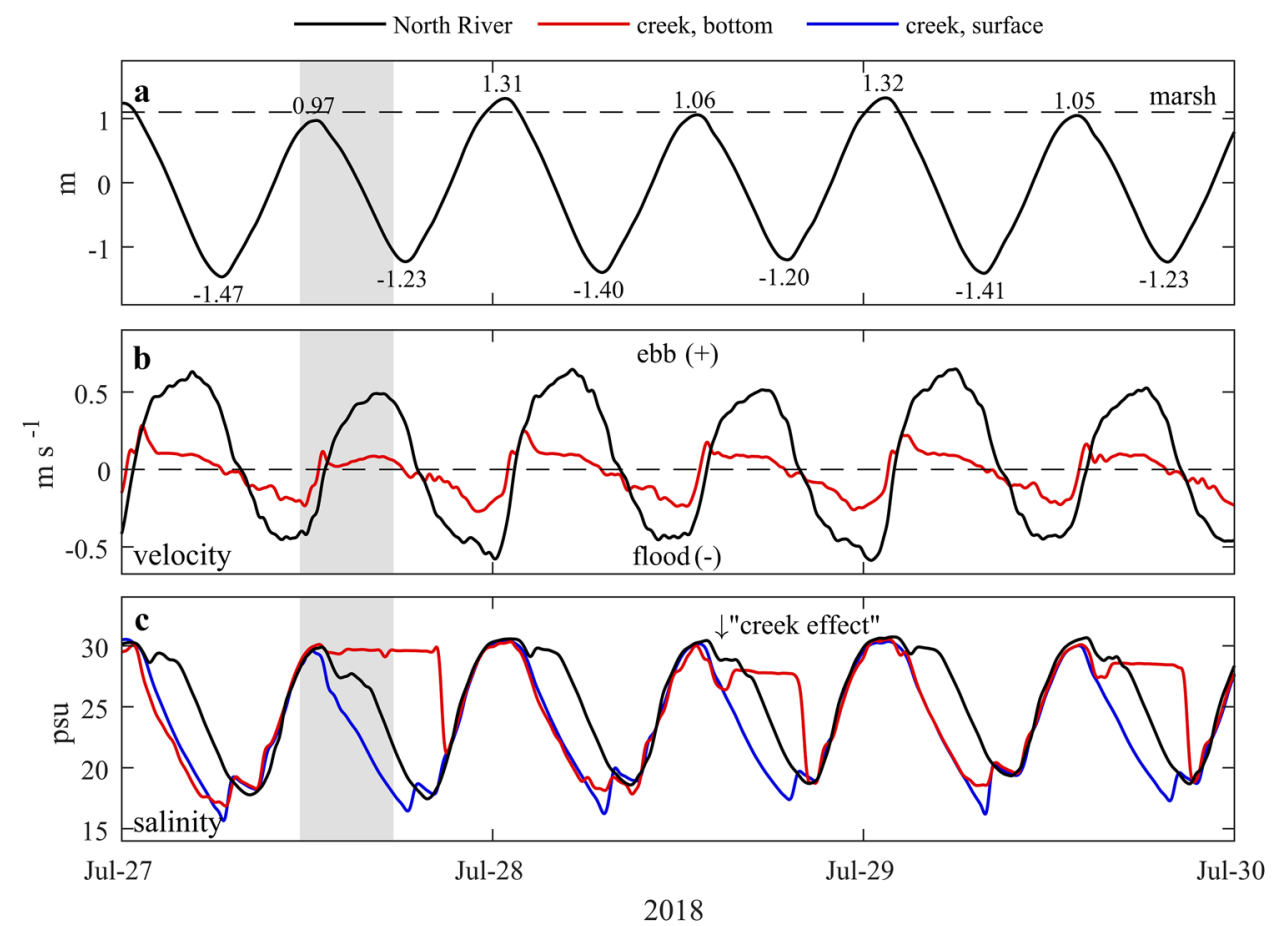
During periods of flood tide, the salinities in the main channel and the tributary creek are nearly identical. Essentially, the creek inherits its salinity structure from its timedependent boundary with the main channel during flood tide (Warner et al. 2002). However, as the tide begins to fall, the creek starts ebbing while the main channel continues to flood. During the surveys on July 27, the creek began ebbing $31 \mathrm{~min}$ before the main channel. Due to this phase difference, the creek remains consistently fresher than the adjacent main channel over a tidal cycle since the saltiest water which passes the junction in the main channel never enters the creek. The salinity of the outflowing creek water drops as it ebbs into the main channel because of the axial salinity gradient that the creek obtained from the main channel during flood tide. The relatively fresh creek outflow alters the salinity of the main channel relative to the purely advective influence of the flooding tide. Although the volume transport from the creek is small compared to the main channel, the salinity difference between the creek and main channel is large - up to 6 psu over a horizontal distance of about $150 \mathrm{~m}$. Thus, the out-of-phase exchange between the main channel and the creeks contributes to the "creek effect"- a salinity deficit in the main channel through the early ebb tide.

\section{Structure of the Creek Plume}

The structure of the creek outflow into the main channel is readily observed in the aerial imagery. A snapshot from the drone footage (Fig. 9a) reveals a visible surface plume exiting from the creek into the main channel during early ebb. The distinct color difference between the brown outflowing creek water and the relatively blue main channel water provides a clear visualization of the trajectory of the creek water as it enters the main channel. The creek plume spans the entire width of the main channel and is sharply separated from the water of the main channel by a convergent surface front on the upstream side of the creek plume. Video footage shows that surface drifters which encountered the surface front continued to follow it as they moved downstream (right of image). On the downstream side of the creek junction, the creek plume is also sharply separated from the main channel water, where a circulation zone was observed. The results from PTV show that the creek outflow reached velocities of up to $0.7-0.9 \mathrm{~m} \mathrm{~s}^{-1}$ at the inside of the bend apex, while velocities in the main channel were still $0.1-0.2 \mathrm{~m} \mathrm{~s}^{-1}$.

Shipboard measurements during the period of drone observations reveal further details of the velocity and salinity structure at the creek junction (Fig. 10). At the
Fig. 9 (a) Aerial drone imagery taken during early ebb in spring conditions. The creek outflow is from bottom of the image towards the top, while currents in the main channel are from left to right. (b) Grayscale image with surface drifter trajectories and velocity magnitudes from PTV

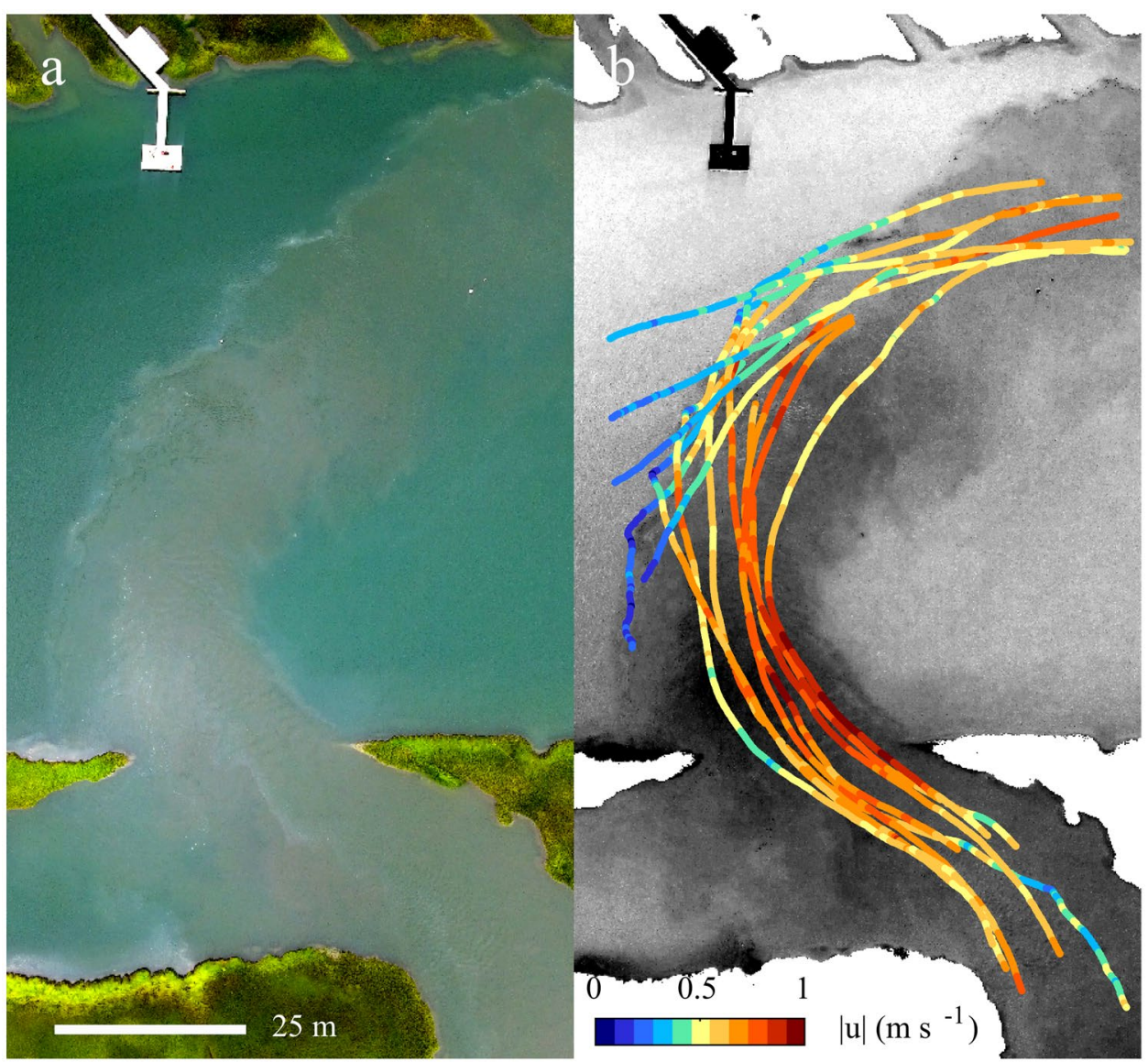


mouth of the creek, the velocities reach maximum magnitudes of $0.6-0.7 \mathrm{~m} \mathrm{~s}^{-1}$. The slightly larger velocity values obtained from the drone PTV analysis compare favorably, given that the ADCP could not measure velocity in the upper $0.5 \mathrm{~m}$ of the water column and that the creek outflow is sheared. The salinity of the creek plume is about 30.2 psu while the main channel is about 31.2 psu (Fig. 10e). This salinity difference is much less than the maximum observed values from the creek and main channel moorings, indicating the presence of significant mixing between the creek mooring at CB 1 and the creek junction with the main channel. The creek outflow introduces a local freshwater anomaly into the longitudinal salinity distribution of the main channel. Between the creek water and the downstream end of the channel (towards B' in Fig. 10f) the local horizontal salinity gradient is about $50 \mathrm{psu} \mathrm{km}^{-1}$, indicating a strong front. The salinity inversions evident in the nearly vertical isohalines suggest the presence of intense turbulent mixing and flow instabilities.

\section{Shear and Stratification in the Creek}

In this section, we examine the tidal variation of shear and stratification in the creek. Figure 11 shows measurements at the CB1 mooring-located behind the sill-from the same 4-day period as the salt flux decomposition. We align the time-series of velocity, salinity, and the instantaneous local salt flux $\left(\int u_{2} s_{2} d A\right)$ from multiple tidal cycles based on the start of flood tide in the creek. An important distinction between this period of neap conditions and the one during the shipboard surveys is that for this period, the creek remains stratified on each ebb tide as opposed to alternating between well-mixed and stratified conditions on individual tides. The persistent stratification of

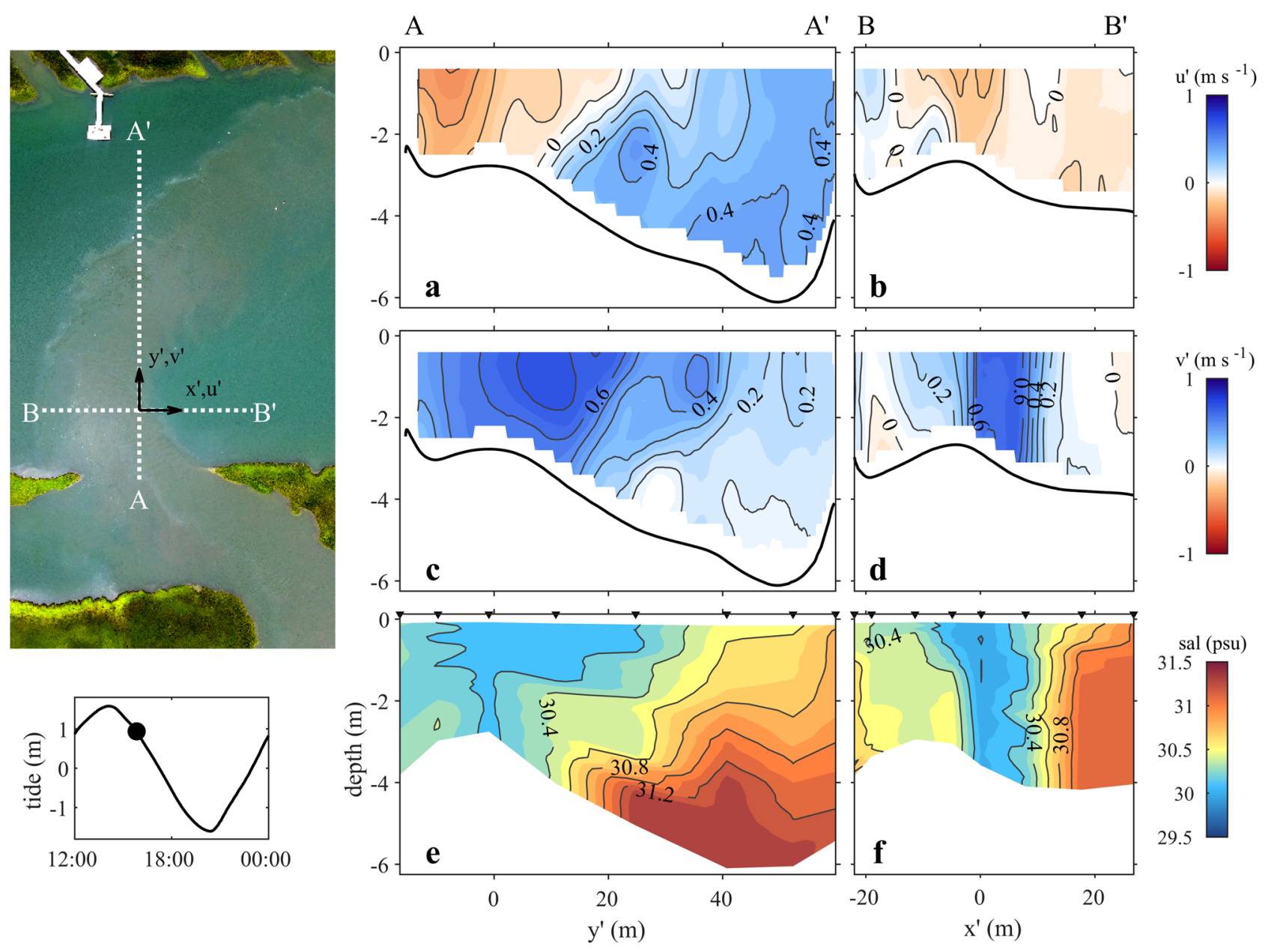

Fig. 10 Shipboard measurements obtained during drone survey. Map of transects A-A' and $\mathbf{B}-\mathbf{B}$ ' and the corresponding horizontal coordinate system for velocities is shown in the upper left. The time of the shipboard and drone survey is indicated by the black circle on the tidal time series in the bottom left. The panels show $(\mathbf{a}, \mathbf{b})$ velocity in the streamwise direction of the main channel, $u^{\prime}$, where blue is ebb, red is flood; (c, d) velocity in the direction of the creek outflow, $v^{\prime}$, where blue is out, red is in; and (e, f) salinity, where black triangles along the top axis indicate CTD casts 

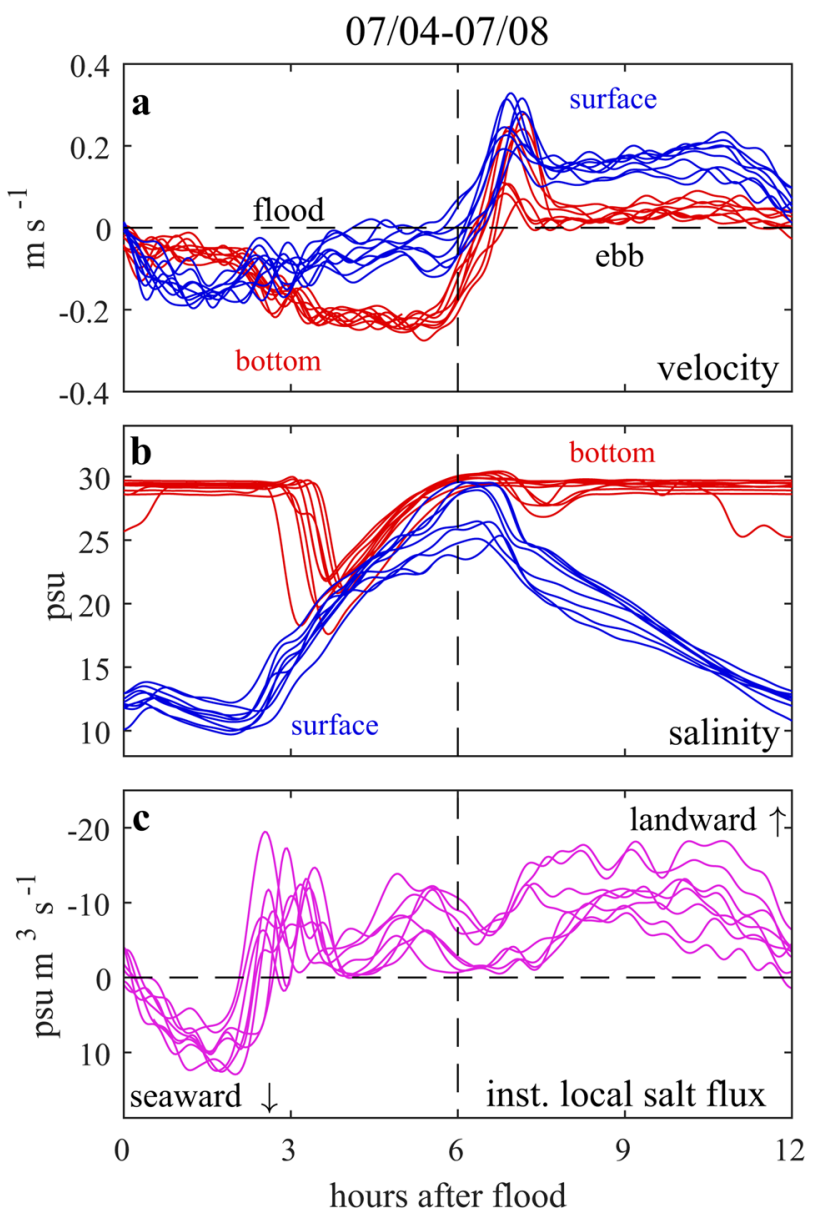

Fig. 11 Tidal hour plots of (a) velocity, (b) salinity, and (c) local salt flux due to vertical correlations between velocity and salinity in the creek. Hours $0-6$ correspond roughly to flood tide and hours 6-12 to ebb. Time-series are from mooring CB1, located behind the sill near the mouth of Cove Brook

the creek may result from slightly weaker tidal velocities and a stronger axial salinity gradient in the creek for this period, which enable a stronger baroclinic circulation.

At the beginning of flood tide (hours 0-3), water from the main channel enters the creek over the sill. The abrupt change in channel depth at the sill, in combination with the stratification leftover from the end of the previous ebb, causes flow separation of the surface layer over the blocked bottom layer behind the sill. This is the only time when the instantaneous local salt flux is seaward due to a combination of shear and stratification. From hours 3-6, the increasing water level reduces the relative change in channel depth at the sill and diminishes the flow separation effect. As the salinity increases, the bottom layer accelerates while the surface layer slows down, consistent with the advance of a salt wedge and the influence of a baroclinic pressure gradient (Geyer and Farmer 1989). During early ebb (hours 6-8), there is a sudden acceleration over the entire water column when the currents change direction from flood to ebb. The abruptness of the early ebb acceleration suggests a nonlinear process. Estimates of the water surface slope between the moorings CB1 in the creek and NR2 in the main channel indicated a large barotropic pressure gradient near hour 6, which may be related to the adjustment of the lateral surface slope in the main channel due to faster flood currents on the inside of the meander bend near the creek junction (see Kranenburg et al. 2019 for discussion of the lateral dynamics). The early ebb acceleration is followed by the development of a strongly sheared velocity profile in which the bottom layer is nearly stagnant from hours 8-12. The two-layer flow is accompanied by a strong, persistent pattern of stratification, in which the surface layer becomes fresher while the bottom layer retains its high salinity. The structure of shear and stratification in the creek is consistent with an estuarine exchange flow, which drives a landward salt flux from hours 3-12. Notably, this baroclinic circulation exists despite the absence of any significant freshwater source from the head of the creek; rather, it is driven by the baroclinic pressure gradient inherited from the main channel.

\section{Analysis}

\section{Quantifying the Salinity Anomaly Due to the Creeks}

In the absence of the creeks, the salinity variation in the main channel would be dominated by the along-channel advection. The salinity anomaly observed in the main channel during ebb tide results from the relatively fresh water reintroduced to the main channel by the creek outflows. We quantified the magnitude of the anomaly from the shipboard surveys by comparing the measured salinity to a "background" value which would have been observed in the absence of the creek outflows. To estimate this background salinity, we advected the salinity from the most landward transect downstream using the velocity field from the ADCP measurements. We assumed that the salinity field at the landward transect remains undisturbed by the creeks because it is far enough upstream from the creek mouths based on the tidal excursion over the brief period of the flood tide during which the creek discharges into the main channel. Although our shipboard measurements only spanned the ebb tide, our moored observations indicate this is the only part of the tidal cycle during which the creeks alter the salinity structure in the main channel, thus there would be no salinity anomaly caused by the creeks during the flood tide.

To calculate the cross-section averaged values of velocity and salinity, we interpolated the measurements over a regularly spaced grid $(\Delta y=1 \mathrm{~m}, \Delta z=0.1 \mathrm{~m})$. Near the vertical boundaries, we used a parabolic fit to the two nearest 
available data points to extrapolate velocity measurements to the surface and bottom using zero stress and no-slip boundary conditions, respectively. Similarly, we used a parabolic fit to extrapolate surface and bottom salinity measurements using no-flux conditions. While using the cross-section averaged values to estimate the kinematics is a simplification, a comparison of the salt flux through each cross-section with the product of the cross-section averaged salinity and volume transport indicated less than $2 \%$ difference. This is because of nearly well-mixed conditions in the main channel.

To obtain the background salinity field, we numerically evaluated the 1-D transport equation using a Lax-Wendroff advection scheme (second-order accurate in space and time, Lax and Wendroff 1960). Cross-sectionally averaged velocity at each transect was interpolated with a cubic spline fit over a regular time record at intervals of $\Delta t=60 \mathrm{~s}$ to provide an estimate of the velocity field. We used salinity measurements from the first survey (before beginning of ebb tide) as the initial condition and from the most landward transect as the upstream boundary condition. A one-sided difference was used at the downstream boundary except during flood tide when the salinity at the most seaward transect was used as an inflow boundary condition.

We define the salinity anomaly $\Delta s(x, t)$ as the difference between the measured salinity and the estimated background salinity (Fig. 12). The evolution of $\Delta s$ through space and time shows how the fresher water from the two creeks, Stony Brook (SB) and Cove Brook (CB), enters the main channel and then is transported downstream. The salinity deficit (negative $\Delta s$ ) due to Stony Brook peaks at around 13:30, about 15 min earlier than Cove Brook. A second, smaller $\Delta s$ plume from Cove Brook enters around 17:00, corresponding to the second peak in creek velocity observed in Fig. $8 \mathrm{~b}$. The combined inflows from the creeks reduce the salinity in the main channel by a maximum anomaly of 0.8 psu at about 14:00. These freshwater anomalies mix and are transported downstream; thus, the creek effect influences regions downstream of the junctions but does not impact the upstream reaches significantly. By reducing the salinity of the main channel during the ebb tide, the trapping mechanism in the creeks produces a landward tidal salt flux.

\section{Calculating the Dispersion Due to Trapping}

The dispersion rate corresponding to the exchange between the creeks and the main channel is obtained from the tidal correlation between the cross-sectionally averaged, tidally varying velocity $u_{1}$ and the salinity anomaly $\Delta s$,

$-K_{\text {creek }} A_{0}\left(\frac{\partial s_{0}}{\partial x}\right)=F_{\text {creek }}=\left\langle\int u_{1} \Delta s d A\right\rangle$.

In this way, we isolate the component of the nonlocal salt flux in the main channel due to the creek effect. To calculate the tidal average, we divide the integral term in Eq. (10) by $T=12.4 \mathrm{~h}$, the M2 tidal period, since we assume that $\Delta s=0$ through the flood tide. For consistency with the values of the effective dispersion $K$ determined from the subtidal salt balance, we use the same value of the along-axis salinity gradient $\partial s_{0} / \partial x=2.2 \mathrm{psu} \mathrm{km}^{-1}$ to calculate $K_{\text {creek }}$. To estimate the error due to the resolution of our measurements, we applied a bootstrapping method by repeating the calculation of the background salinity field while neglecting velocity and salinity data from a single transect for each instance. At transect 5, which coincides with the mooring NR2, the nonlocal salt flux due to the exchange with the creeks was estimated to be $F_{\text {creek }}$ psu $\mathrm{m}^{3} \mathrm{~s}^{-1}$, corresponding to the dispersion rate $K_{\text {creek }}=22 \pm 0.8 \mathrm{~m}^{2} \mathrm{~s}^{-1}$ (Fig. 13).
Fig. 12 Salinity evolution over space and time from (a) shipboard measurements and (b) estimated background value in the absence of the creek effect. The salinity anomaly shown in $\mathbf{c}$ is the difference between the two. The junctions of Cove Brook (CB) and Stony Brook (SB) with the main channel are designated by the vertical dashed lines. Individual surveys are indicated by the black dots in (a)
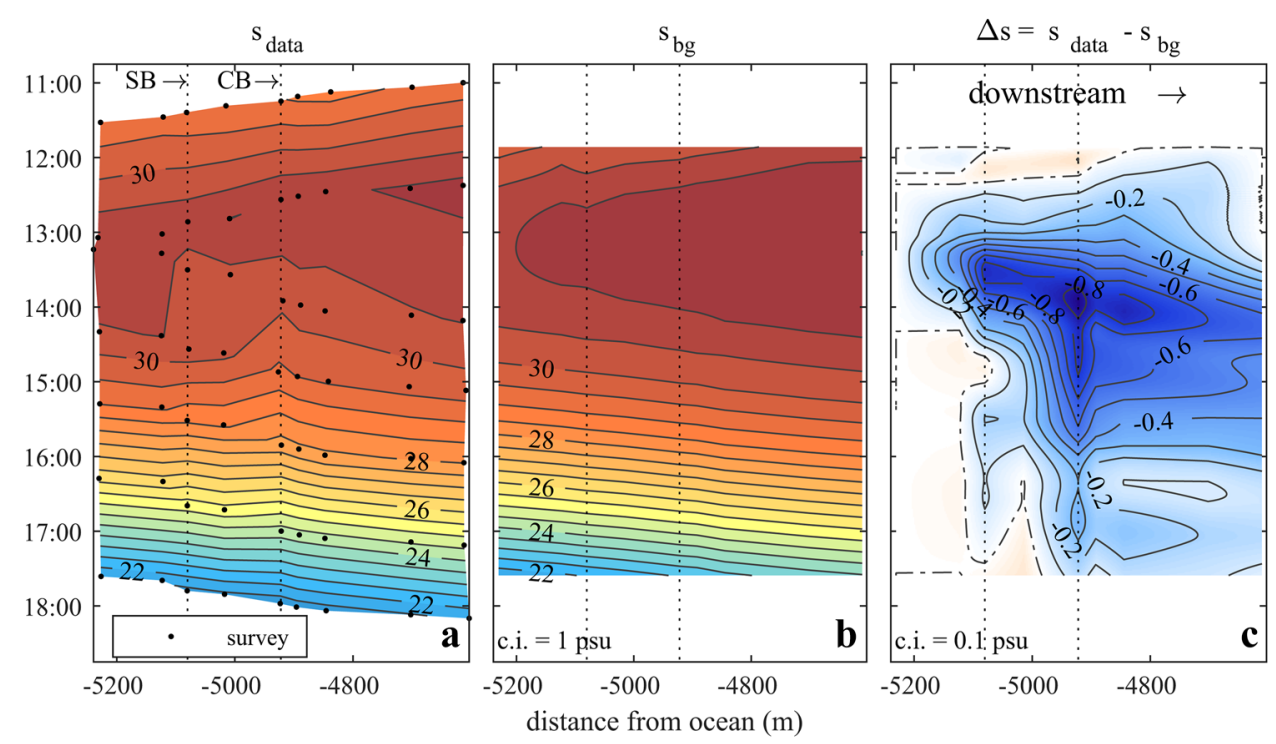


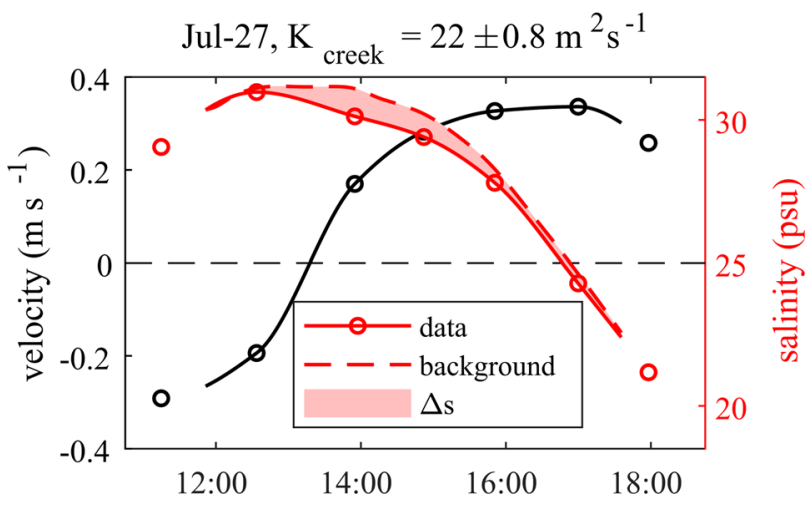

Fig. 13 Time-series of velocity (black line), salinity (red lines), and salinity anomaly (red shading) at transect 5 . The dispersion rate due to trapping in the creeks is calculated from the tidal correlation between the salinity anomaly and the tidal velocity

However, we note the effects of the diurnal inequality on the salt flux in the creek, which alternates between net landward and seaward directions on subsequent tidal cycles. Since the shipboard surveys were conducted during daytime when the tides were small and the exchange flow in the creek was strong, the net salt flux in the creek was landward, i.e., the creek gained salt. This is consistent with observations of high salinity water trapped behind the sill. Thus, $F_{\text {creek }}$ includes the contribution from both the trapping mechanism and the net salt flux into the creek since both produce a negative salinity anomaly in the main channel.

To obtain a proper estimate of the dispersive contribution of the trapping mechanism for an individual tidal cycle, we must first remove the effect of the net salt flux into or out of the creeks for that cycle from the total value of $F_{\text {creek }}$. We estimate the net salt flux into Cove Brook for this tidal cycle by scaling a value from the period of resolved salt fluxes by the salinity range during the period of shipboard surveys. Using an average value of $3 \mathrm{psu}^{3}$ $\mathrm{s}^{-1}$ for the tidal cycles when the net salt flux was landward in Cove Brook (see Fig. 6b) and salinity ranges of 20 psu (period of resolved salt fluxes) and 15 psu (shipboard surveys), we estimate a net landward salt flux of $2.2 \mathrm{psu} \mathrm{m}^{3}$ $\mathrm{s}^{-1}$ in Cove Brook for the period of shipboard surveys on July 27. We estimate the net salt flux into Stony Brook as roughly half that value based on its cross-sectional area and obtain a total landward salt flux into both creeks of 3.3 psu $\mathrm{m}^{3} \mathrm{~s}^{-1}$. Subtracting this value from $F_{\text {creek }}$, we obtain $F_{\text {trap,creek }} \approx 9.7 \mathrm{psu} \mathrm{m}^{3} \mathrm{~s}^{-1}$, with a corresponding dispersion rate of $K_{\text {trap,creek }} \approx 16 \mathrm{~m}^{2} \mathrm{~s}^{-1}$. Based on this result, the trapping mechanism accounts for more than half the effective dispersion rate, $K=23 \mathrm{~m}^{2} \mathrm{~s}^{-1}$ (Fig. 4e), required to balance the advective river flow near the creek junction for this tidal cycle.

\section{Discussion}

\section{Comparison with Theory}

Here, we compare our empirical estimate of dispersion due to the creek effect to theoretical estimates from Okubo (1973) and MacVean and Stacey (2011). Representative values of the tidal velocities, cross-sectional area, and velocity phase differences in the North River, Cove Brook, and Stony Brook from conditions on July 27 are shown in Table 1 . For each creek, we estimated the ratio of the trap volume to channel volume as $r=\left(U_{\text {creek }} A_{\text {creek }}\right) / U A$ where $U$ and $A$ are tidal velocities and cross-sectional areas, respectively, and the ratio of salt transport in the creeks to the main channel as $\epsilon=r\left(s_{0, \text { creek }} / s_{0}\right)$, where we use $s_{0, \text { creek }} / s_{0} \approx 0.9$.

In selecting the Okubo (1973) exchange rate $k$, we consider here a possible range of values based on how the trap residence timescale $k^{-1}$ relates to dispersion in the main channel. We note that using a timescale of one tidal period, as done by MacVean and Stacey (2011), would overestimate the dispersion due to trapping because a parcel of fluid which enters and stays in a trap for one tidal period would return to the same body of water from which it originated in the main channel, thus resulting in zero dispersion. Therefore, we suggest a maximum residence timescale of one-half a tidal period, since that corresponds to the largest possible displacement between a parcel of fluid which enters and exits a trap and a corresponding parcel which remains in the main channel. At residence timescales greater than one half a tidal period, the oscillatory currents in the main channel will decrease the displacement between the two parcels. In this case, the effective dispersion given by Eq. (1) would correspond to a timescale shorter than one half a tidal period. Thus, we suggest that for branching channel systems such as the North River, the appropriate choice of a residence timescale $k^{-1}$ should only range from a minimum value of the velocity phase difference between the traps and main channel to a maximum of half a tidal period.

Applying our representative field values to Eqs. (1) and (2) yields trapping dispersion rates for the Okubo (1973) expression: $K_{\text {trap,D }} \approx 10-34 \mathrm{~m}^{2} \mathrm{~s}^{-1}$ and for the MacVean and Stacey (2011) expression: $K_{\text {trap }, \mathrm{A}} \approx 7.9 \mathrm{~m}^{2} \mathrm{~s}^{-1}$ (see

Table 1 Representative field values of tidal velocity, cross-sectional area, volume ratio, and velocity phase difference in the North River, Cove Brook, and Stony Brook on July 27

\begin{tabular}{llll}
\hline Variable & North River & Cove Brook & Stony Brook \\
\hline$U\left(\mathrm{~m} \mathrm{~s}^{-1}\right)$ & 0.4 & 0.15 & 0.08 \\
$A\left(\mathrm{~m}^{2}\right)$ & 280 & 50 & 30 \\
$r$ & - & 0.067 & 0.021 \\
$\alpha$ (min, degrees) & - & $31,15^{\circ}$ & 44,22 \\
\hline
\end{tabular}


Table 2 for summary of dispersion values). Based on the similarity between the lower limit of the Okubo (1973) estimates and the value from the MacVean and Stacey (2011) estimate, it appears that the two parametrizations become nearly equivalent when the appropriate exchange timescale is selected to represent the velocity phase difference between the main channel and traps. This suggests that the minimum dispersion associated with trapping in the creeks is achieved if there is only an out-of-phase advective exchange between the main channel and creeks. Our empirical result $K_{\text {trap,creek }} \approx 16 \mathrm{~m}^{2} \mathrm{~s}^{-1}$ is twice as large as the advective parametrization $K_{\text {trap,A }}$ and about $60 \%$ larger than the advective lower limit for $K_{\text {trap,D }}$. This difference implies that trapping in the North River is impacted by additional transport processes in the creeks. In the following section, we investigate the mechanism of exchange flow in the creeks and the role it plays in supplementing the dispersion associated with trapping.

\section{Mechanism of Exchange Flows in the Creeks}

First, we consider the conditions leading to the development of the baroclinic circulation in the creeks, which-somewhat paradoxically-exists despite the absence of a significant freshwater source at the head of the creek. The time variation of salinity in both the creek and the main channel are dominated by advection. Since the creeks inherit their axial salinity structure during flood tide from their time-dependent boundaries at their junctions with the main channel, the tidal variation of salinity must be exactly the same at the junctions between the main channel and the creeks. However, velocities in the main channel are larger than in the creeks. Thus, the axial salinity gradient in the creeks must be commensurately larger, scaling as $\partial s_{\text {creek }} / \partial x \sim\left(U / U_{\text {creek }}\right) \partial s / \partial x$. Since tidal currents in the creek are 3-5 times smaller in magnitude than those in the main channel, the salinity gradient must therefore be 3-5 times larger in the creeks.

This strong axial salinity gradient in the creek drives a baroclinic exchange flow that is directed landward at depth and seaward at the surface, which strains the axial salinity gradient and stratifies the creeks. The conditions for stratification in the main channel and the creeks can be compared by evaluating the Simpson number, as defined in Eq. (11):

$\mathrm{Si}=\frac{\beta g\left(\partial s_{0} / \partial x\right) H^{2}}{C_{D} U^{2}}$

where $\beta=7.7 \times 10^{-4} \mathrm{psu}^{-1}$ is the coefficient of haline contraction, $g$ is acceleration due to gravity, $H$ is the channel depth, and $C_{D} \simeq 3 \times 10^{-3}$ is a quadratic drag coefficient (Simpson et al. 1990). Si can be regarded as the ratio between the baroclinic pressure gradient, which drives an exchange flow that stratifies the water column, and the stress divergence, which retards the exchange flow. Larger values of $\mathrm{Si}$ are associated with persistent stratification whereas smaller values are associated with well-mixed conditions (Stacey et al. 2001). Estimates from field conditions on July 27 result in values of $\mathrm{Si}_{\mathrm{NR}} \simeq 0.55$ in the North River, $\mathrm{Si}_{\mathrm{CB}} \simeq 4.1$ in Cove Brook, and $\mathrm{Si}_{\mathrm{SB}} \simeq 17$ in Stony Brook. In comparison to the main channel, $\mathrm{Si}$ in the creeks is significantly larger because the weaker currents both increase the baroclinic pressure gradient and decrease the stress divergence, thus sustaining the robust estuarine exchange flow observed in the creeks.

The baroclinically driven exchange flow and stratification act in concert to enhance the dispersion due to trapping by sharpening the salinity contrast between the outflowing creek water and the main channel. Stratification inhibits turbulent mixing (Bowden 1965), resulting in strong shear between the surface and bottom layers of the creeks. The exchange flow accelerates the ebbing currents in the surface layer of the creeks, effectively increasing their phase difference with the main channel. Like "playing off the bottom of the deck," the exchange flow in the creek enables fresher water that enters the creek during early flood tide to be fasttracked back into the main channel once the ebb tide begins. This rapid reintroduction of relatively fresh water into the main channel amplifies the magnitude of the negative salinity anomaly through ebb tide, thus augmenting the dispersion caused by the trapping mechanism.
Table 2 Calculated values of effective dispersion and dispersion due to tidal trapping using different methods. Diffusive trapping is from Okubo (1973) and advective trapping from (MacVean and Stacey 2011)

\begin{tabular}{lll}
\hline Dispersion & Description & Value $\left(\mathrm{m}^{2} \mathrm{~s}^{-1}\right)$ \\
\hline$K$ & Effective, Eq. (3) & 23 \\
$K_{\text {creek }}$ & Salinity anomaly flux, Eq. (10) & 22 \\
$K_{\text {trap,creek }}$ & Salinity anomaly flux minus estimate of net salt flux in creek & 16 \\
$K_{\text {trap,D }}$ & Diffusive trapping, Eq. (1) with velocity phase difference for $k^{-1}$ & 10 \\
$K_{\text {trap,D }}$ & Diffusive trapping, Eq. (1) with one half a tidal period for $k^{-1}$ & 34 \\
$K_{\text {trap,A }}$ & Advective trapping, Eq. (2) & 7.9 \\
$K_{\text {trap,ex }}$ & Maximum nonlocal contribution from exchange flow in the creek & 9.1 \\
$K_{\text {trap,A+ex }}$ & Advective trapping, Eq. (2) plus the maximum nonlocal contribution & 17 \\
& from exchange flow in the creek & \\
\hline
\end{tabular}




\section{Nonlocal Salt Flux in the Main Channel}

Because of advection by the tidal currents, the local salt flux due to the exchange flow and stratification in the creek contributes to the nonlocal salt flux in the main channel. Dronkers and van de Kreeke (1986) showed how the nonlocal salt flux at a fixed cross section is equal to the difference between the local salt flux in a plane moving with the tides about that cross-section and the local salt flux at the fixed location. At each creek junction, the moving planes in the main channel will have to split such that a segment enters that creek, thus sampling the local salt fluxes within it. The exchange between the main channel and the creeks thus influences the region within a tidal excursion of the creek junction, where differences between the distinct dispersive regimes of the highly stratified creeks and the well-mixed main channel are communicated via the nonlocal salt flux. The exchange flow in the creeks contributes most strongly to the nonlocal salt flux in the main channel near the junctions, where the moving planes which split and enter the creeks spend a significant fraction of the tidal period sampling the relatively high local salt flux in the creeks.

To obtain an estimate of the local salt flux in the creek during the period of shipboard surveys, we apply the same scaling approach used earlier to estimate the net salt flux from the creeks. By scaling the local salt flux from the period of resolved fluxes (about $5 \mathrm{psu} \mathrm{m}^{3} \mathrm{~s}^{-1}$ based on Fig. 6b) by the salinity range on the day of shipboard surveys, we estimate a local salt flux in Cove Brook of about $3.8 \mathrm{psu} \mathrm{m}^{3} \mathrm{~s}^{-1}$. Assuming about half that value in Stony Brook, we estimate the maximum contribution of the exchange flow in the creeks to nonlocal salt flux in the main channel would be $5.7 \mathrm{~m}^{3} \mathrm{~s}^{-1}$, corresponding to a dispersion rate of $K_{\text {trap,ex }}=9.1$ $\mathrm{m}^{2} \mathrm{~s}^{-1}$. Adding this value to the estimate from the out-ofphase advective parametrization $K_{\text {trap, }}$ results in a combined dispersion rate of $K_{\text {trap,A+ex }}=17 \mathrm{~m}^{2} \mathrm{~s}^{-1}$, which is close to our empirical result of $K_{\text {trap,creek }}=16 \mathrm{~m}^{2} \mathrm{~s}^{-1}$. Evidently, the exchange flow in the creeks significantly enhances the trapping mechanism.

The spatial influence of the trapping mechanism on nonlocal salt flux - and thus, dispersion - in the main channel can be inferred from our estimate of the salinity anomaly. To produce the negative salinity anomaly in the main channel, the trapping mechanism essentially exchanges a volume of water seaward from the creek junction with a volume of relatively fresher water landward from the junction. This results in a dispersive downgradient salt flux, which locally reduces the axial salinity gradient in the vicinity of the creek junction in the main channel. Since all the negative salinity anomaly passes through the main channel at the creek junction, the dispersion due to the creek effect is maximal at the junction. Downstream (seaward) from the junction, the salinity anomaly which enters the main channel is advected downstream by the ebb tide. Therefore, the dispersion due to the creek effect will vary from its maximum value of 16 $\mathrm{m}^{2} \mathrm{~s}^{-1}$ at the creek junction to zero at a distance one tidal excursion away from the junction.

\section{Other Mechanisms of Dispersion}

While the tidal trapping mechanism contributes significantly to the effective dispersion rate near the creek junctions, other sources of nonlocal salt flux must exist to maintain the salt balance throughout the estuary. Near the mouth, it is likely that jet-sink exchange at channel expansions would be important for driving the landward salt flux (Stommel and Farmer 1952; Signell and Butman 1992; Chen et al. 2012). The meandering planform geometry of the main channel may also enhance lateral shear dispersion (Fischer 1969), especially in sharp bends where flow separation occurs (Bo and Ralston 2020). Tidal trapping in the shoals near the mouth (Ralston and Stacey 2005) and the surrounding salt marsh could also contribute to dispersion (Ridd et al. 1990; Vallino and Hopkinson 1998); however, the dispersive effect of the salt marsh is limited to spring conditions when the marsh is significantly inundated (Dronkers 1978).

\section{Implications of the Exchange Flow in the Creeks}

The enhancement of the tidal trapping dispersion by the exchange flow in the creeks represents a mechanism which may play an important role in other multi-channel estuary systems, such as salt marsh tidal creek networks like the Coos Estuary (Conroy et al. 2019) and the Plum Island Sound Estuary (Vallino and Hopkinson 1998), as well as in urbanized estuaries with various human-made ports and side channels like Newark Bay (Corlett and Geyer 2020). However, the impact of the exchange flow in the side channels on dispersion in the main channel will depend strongly on the geometry of the side channel-if it is too small, then the volumetric exchange with the main channel will be minimal and thus the total contribution to the dispersive salt flux will be negligible, but if it is too large, then the tidal velocities can become similar to the main channel and thus the axial salinity gradient-which drives the exchange flow in the side channel-will not be significantly enhanced. Additionally, as the side channel becomes longer, the tidal velocity phase difference between it and the main channel decreases, which also reduces dispersion by trapping.

In addition to enhancing dispersion, the exchange flows also stratify the creeks and greatly amplifies the volumetric exchange with the main channel, which could potentially impact the biogeochemistry of multi-channel estuary systems. For example, Nicholson et al. (2018) observed notable differences between salinity-methane and salinity- $\mathrm{CO}_{2}$ relationships in the North River and Cove Brook. By increasing 
the volumetric transport between the main channel and the creeks, the exchange flow in the creeks therefore influences the nutrient distribution in the estuary system.

\section{Conclusions}

For short estuaries such as the North River where the tidal excursion is similar in length to the salinity intrusion, local morphological features such as side channels can contribute significantly to a landward nonlocal salt flux, which is balanced by the seaward river flow. In multi-channel systems, the trapping mechanism describes the out-of-phase exchange between the main channel and side channels, which produces a dispersive salt flux by introducing relatively fresh water from the side channels back to the main channel during the ebb tide. If tidal currents are weaker in the side channels than in the main channel, the axial salinity gradient in the side channels must be correspondingly larger than in the main channel. Therefore, even if turbulent mixing due to tidal currents is sufficient to suppress an estuarine exchange flow in the main channel, the combination of a stronger axial salinity gradient and weaker mixing may still enable an exchange flow to develop in the side channels. Notably, this baroclinic circulation can exist even without freshwater sources at the heads of the side channels. By fast-tracking fresher surface water back to the main channel, the exchange flow in the side channels sharpens the salinity contrast between the main channel and the outflow from the side channels, thus enhancing the dispersion due to trapping.

Acknowledgements This project was funded by NSF Grant OCE1634490 . This material is based upon work supported by the National Science Foundation Graduate Research Fellowship under Grant No. \#1122374. The authors thank Wouter Kranenburg and Dave Ralston for fieldwork assistance and helpful discussions, Jay Sisson for technical field assistance in the field, and Peter Traykovski for providing the bathymetry and drone video. The authors also thank Dr. Lissa MacVean and 2 anonymous reviewers for their suggestions and feedback on improving the manuscript.

Open Access This article is licensed under a Creative Commons Attribution 4.0 International License, which permits use, sharing, adaptation, distribution and reproduction in any medium or format, as long as you give appropriate credit to the original author(s) and the source, provide a link to the Creative Commons licence, and indicate if changes were made. The images or other third party material in this article are included in the article's Creative Commons licence, unless indicated otherwise in a credit line to the material. If material is not included in the article's Creative Commons licence and your intended use is not permitted by statutory regulation or exceeds the permitted use, you will need to obtain permission directly from the copyright holder. To view a copy of this licence, visit http://creativecommons.org/licenses/by/4.0/.

\section{References}

Aris, R. 1956. On the dispersion of a solute in a fluid flowing through a tube. Proceedings of the Royal Society of London, Series A: Mathematical, Physical and Engineering Sciences 235: 67-77. https://doi.org/10.1098/rspa.1956.0065.

Banas, N.S., B.M. Hickey, P. MacCready, and J.A. Newton. 2004. Dynamics of Willapa Bay, Washington: A highly unsteady, partially mixed estuary. Journal of Physical Oceanography 34: 2413-2427. https://doi.org/10.1175/JPO2637.1.

Bo, T., and D.K. Ralston. 2020. Flow separation and increased drag coefficient in estuarine channels with curvature. Journal of Geophysical Research: Oceans 125: 1-25. https://doi.org/10.1029/ $2020 \mathrm{jc} 016267$.

Bowden, K.F. 1964. The mixing processes in a tidal estuary. Advances in Water Pollution Research, Vol. 7 of, Elsevier, 329-346.

Bowden, K.F. 1965. Horizontal mixing in the sea due to a shearing current. Journal of Fluid Mechanics 21: 83-95. https://doi.org/ 10.1007/BF00167972.

Chatwin, P.C. 1975. On the longitudinal dispersion of passive contaminant in oscillatory flows in tubes. Journal of Fluid Mechanics 71: 513-527.

Chatwin, P.C. 1976. Some remarks on the maintenance of the salinity distribution in estuaries. Estuarine and Coastal Marine Science 4: 555-566. https://doi.org/10.1016/0302-3524(76)90030-X.

Chen, S.-N., W.R. Geyer, D.K. Ralston, and J.A. Lerczak. 2012. Estuarine exchange flow quantified with isohaline coordinates: Contrasting long and short estuaries. Journal of Physical Oceanography 42: 748-763. https://doi.org/10.1175/JPO-D-11-086.1.

Conroy, T., D.A. Sutherland, and D.K. Ralston. 2019. Estuarine exchange flow variability in a seasonal, segmented estuary. Journal of Physical Oceanography 595-613, https://doi.org/10.1175/ jpo-d-19-0108.1.

Corlett, W.B., and W.R. Geyer. 2020. Frontogenesis at estuarine junctions. Estuaries and Coasts 43: 722-738. https://doi.org/10.1007/ s12237-020-00697-1.

Dronkers, J. 1978. Longitudinal dispersion in shallow well-mixed estuaries. Coastal Engineering 1978, Vol. 73 of, New York, NY, American Society of Civil Engineers, 2761-2777.

Dronkers, J., and J. van de Kreeke. 1986. Experimental determination of salt intrusion mechanisms in the Volkerak estuary. Netherlands Journal of Sea Research 20: 1-19. https://doi.org/10.1016/00777579(86)90056-6.

Fischer, H.B. 1969. The effect of bends on dispersion in streams. Water Resources Research 5: 496-506.

Fischer, H.B. 1976. Mixing and dispersion in estuaries. Annual Review of Fluid Mechanics 8: 107-133. https://doi.org/10.1146/annurev. fl.08.010176.000543.

Fischer, H.B., E.J. List, R.C.Y. Koh, J. Imberger, and N.H. Brooks. 1979. Mixing in Inland and Coastal Waters. Academic, 483 pp.

Friedrichs, C.T. 2011. Barotropic tides in channelized estuaries. Contemporary Issues in Estuarine Physics, A. Valle-Levinson, Ed., Cambridge University Press, 27-61.

Geyer, W.R., and D.M. Farmer. 1989. Tide-induced variation of the dynamics of a salt wedge estuary. Journal of Physical Oceanography 19: 1060-1072. https://doi.org/10.1175/1520-0485(1989) 019\%3c1060:TIVOTD\%3e2.0.CO;2.

Geyer, W.R., and R.P. Signell. 1992. A reassessment of the role of tidal dispersion in estuaries and bays. Estuaries 15: 97. https://doi.org/ $10.2307 / 1352684$.

Hansen, D.V., and M. Rattray. 1965. Gravitational circulation in straits and estuaries. Journal of Marine Research 23: 104-122. https:// doi.org/10.1098/rspb.2009.2214. 
Hughes, F.W., and M. Rattray. 1980. Salt flux and mixing in the Columbia River Estuary. Estuarine and Coastal Marine Science 10: 479-493. https://doi.org/10.1016/S0302-3524(80)80070-3.

Hunkins, K. 1981. Salt dispersion in the Hudson Estuary. Journal of Physical Oceanography 11: 729-738. https://doi.org/10.1175/ 1520-0485(1981)011\%3c0729:SDITHE\%3e2.0.CO;2.

Kranenburg, C. 1986. A time scale for long-term salt intrusion in wellmixed estuaries. Journal of Physical Oceanography 16: 13291331. https://doi.org/10.1175/1520-0485(1986)016\%3c1329: ATSFLT\%3e2.0.CO;2.

Kranenburg, W.M., W.R. Geyer, A.M.P. Garcia, and D.K. Ralston. 2019. Reversed lateral circulation in a sharp estuarine bend with weak stratification. Journal of Physical Oceanography 49: 16191637. https://doi.org/10.1175/JPO-D-18-0175.1.

Lax, P., and B. Wendroff. 1960. Systems of conservation laws. Communications on Pure and Applied Mathematics 13: 217-237. https:// doi.org/10.1002/cpa.3160130205.

Lerczak, J.A., W.R. Geyer, and R.J. Chant. 2006. Mechanisms driving the time-dependent salt flux in a partially stratified estuary. Journal of Physical Oceanography 36: 2296-2311. https://doi. org/10.1175/JPO2959.1.

MacCready, P., and W.R. Geyer. 2010. Advances in estuarine physics. Annual Review of Marine Science 2: 35-58. https://doi.org/10. 1146/annurev-marine-120308-081015.

MacVean, L.J., and M.T. Stacey. 2011. Estuarine dispersion from tidal trapping: A new analytical framework. Estuaries and Coasts 34: 45-59. https://doi.org/10.1007/s12237-010-9298-x.

Nicholson, D.P., A.P.M. Michel, S.D. Wankel, K. Manganini, R.A. Sugrue, Z.O. Sandwith, and S.A. Monk. 2018. Rapid mapping of dissolved methane and carbon dioxide in coastal ecosystems using the ChemYak autonomous surface vehicle. Environmental Science and Technology 52: 13314-13324. https://doi.org/10.1021/ acs.est.8b04190.

Okubo, A. 1973. Effect of shoreline irregularities on streamwise dispersion in estuaries and other embayments. Netherlands Journal of Sea Research 6: 213-224. https://doi.org/10.1016/0077-7579(73)90014-8.

Pritchard, D.W. 1952a. Salinity distribution and circulation in the Chesapeake Bay estuarine system. Journal of Marine Research 11: 106-123.

Pritchard, D.W. 1952b. Estuarine Hydrography. Advances in Geophysics 1: 243-280.

Ralston, D.K., and M.T. Stacey. 2005. Longitudinal dispersion and lateral circulation in the intertidal zone. Journal of Geophysical Research: Oceans 110: 1-17. https://doi.org/10.1029/2005JC002888.

Ralston, D.K., W.R. Geyer, and J.A. Lerczak. 2010. Structure, variability, and salt flux in a strongly forced salt wedge estuary. Journal of Geophysical Research: Oceans 115: 1-21. https://doi.org/10. 1029/2009JC005806.

Ridd, P.V., E. Wolanski, and Y. Mazda. 1990. Longitudinal diffusion in mangrove-fringed tidal creeks. Estuarine, Coastal and Shelf Science 31: 541-554. https://doi.org/10.1016/0272-7714(90)90012-G.

Schijf, J.B., and J.C. Schonfeld. 1953. Theoretical considerations on the motion of salt and fresh water. Proceedings: Minnesota International Hydraulic Convention 321-333.

Signell, R.P., and B. Butman. 1992. Modeling tidal exchange and dispersion in Boston Harbor. Journal of Geophysical Research 97 (C10): 15591-15606. https://doi.org/10.1029/92jc01429.

Simpson, J.H., J. Brown, J. Matthews, and G. Allen. 1990. Tidal straining, density currents, and stirring in the control of estuarine stratification. Estuaries 13: 125. https://doi.org/10.2307/1351581.

Smith, R. 1996. Transport in lungs and branched estuaries. Journal of Fluid Mechanics 325: 331-355. https://doi.org/10.1017/ S0022112096008142.

Stacey, M.T., J.R. Burau, and S.G. Monismith. 2001. Creation of residual flows in a partially stratified estuary. Journal of Geophysical Research: Oceans 106: 17013-17037. https://doi.org/10.1029/ 2000JC000576.

Stommel, H., and H.G. Farmer. 1952. On the nature of estuarine circulation : part I (chapters 3 and 4). Woods Hole Oceanographic Institution.

Streßer, M., R. Carrasco, and J. Horstmann. 2017. Video-based estimation of surface currents using a low-cost quadcopter. IEEE Geoscience and Remote Sensing Letters 14: 2027-2031. https://doi.org/ 10.1109/LGRS.2017.2749120.

Tauro, F., R. Piscopia, and S. Grimaldi. 2019. PTV-Stream: A simplified particle tracking velocimetry framework for stream surface flow monitoring. Catena 172: 378-386. https://doi.org/10.1016/j. catena.2018.09.009.

Vallino, J.J., and C.S. Hopkinson. 1998. Estimation of dispersion and characteristic mixing times in Plum Island Sound estuary. Estuarine, Coastal and Shelf Science 46: 333-350. https://doi.org/10. 1006/ecss.1997.0281.

Warner, J., D. Schoellhamer, J. Burau, and G. Schladow. 2002. Effects of tidal current phase at the junction of two straits. Continental Shelf Research 22: 1629-1642. https://doi.org/10.1016/S02784343(02)00026-2.

Zimmerman, J.T.F. 1986. The tidal whirlpool: A review of horizontal dispersion by tidal and residual currents. Netherlands Journal of Sea Research 20: 133-154. https://doi.org/10.1016/0077-7579(86) 90037-2. 